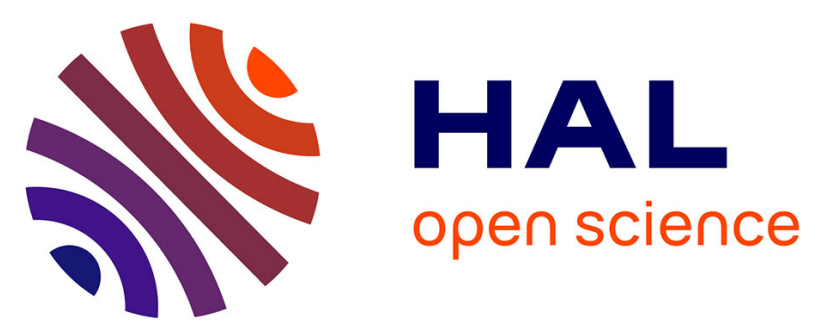

\title{
Monitoring, reporting and verifying emissions in the climate economy
}

\author{
Valentin Bellassen, Nicolas Stephan, Marion Afriat, Emilie Alberola, \\ Alexandra Barker, Jean-Pierre Chang, Caspar Chiquet, Ian Cochran, Mariana \\ Deheza, Christopher Dimopoulos, et al.
}

\section{To cite this version:}

Valentin Bellassen, Nicolas Stephan, Marion Afriat, Emilie Alberola, Alexandra Barker, et al.. Monitoring, reporting and verifying emissions in the climate economy. Nature Climate Change, 2015, 5 (4), pp.319. 10.1038/nclimate2544 . hal-01190149

\author{
HAL Id: hal-01190149 \\ https://hal.science/hal-01190149
}

Submitted on 28 Jun 2021

HAL is a multi-disciplinary open access archive for the deposit and dissemination of scientific research documents, whether they are published or not. The documents may come from teaching and research institutions in France or abroad, or from public or private research centers.
L'archive ouverte pluridisciplinaire HAL, est destinée au dépôt et à la diffusion de documents scientifiques de niveau recherche, publiés ou non, émanant des établissements d'enseignement et de recherche français ou étrangers, des laboratoires publics ou privés. 
Nature Climate Change 5, 319-328 (2015)

4

Valentin Bellassen ${ }^{\mathrm{a}}$, Nicolas Stephan ${ }^{\mathrm{b}}$, Marion Afriat ${ }^{\mathrm{b}}$, Emilie Alberola $^{\mathrm{b}}$, Allexandra Barker ${ }^{\mathrm{c}}$, Jean-Pierre Chang $^{d}$, Caspar Chiquet ${ }^{e}$, Ian Cochran ${ }^{b}$, Mariana Deheza ${ }^{b}$, Christopher Dimopoulos ${ }^{c}$, Claudine Foucherot $^{b}$, Guillaume Jacquier ${ }^{d}$, Romain Morel ${ }^{b}$, Roderick Robinson ${ }^{c}$, Igor Shishlov ${ }^{b}$

\section{Abstract}

This monitoring, reporting and verification (MRV) of greenhouse gas emissions is important for carbon pricing and management mechanisms. Here we review peer-reviewed articles and 'grey literature' related to the costs of MRV. A substantial part of the literature is the regulatory texts of the fifteen most important carbon pricing and management mechanisms currently implemented. Based on a comparison of key criteria such as the scope, cost, uncertainty and flexibility of procedures, we conclude that conventional wisdom on MRV is not often promoted in existing carbon pricing mechanisms. Quantification of emissions uncertainty and incentives to reduce this uncertainty are usually only partially applied, if at all. Further, the time and resources spent on small sources of emissions would be expected to be limited. Although provisions aiming at an effort proportionate to the amount of emissions at stake - 'materiality' - are widespread, they are largely outweighed by economies of scale: in all schemes, MRV costs per ton are primarily driven by the size of the source.

This paper reviews the monitoring, reporting and verification (MRV) of greenhouse gas emissions as it is practiced in the climate economy and is based on the material produced for an upcoming book on the same topic'. 'Climate economy' is here extended to any incentive for a set of economic stakeholders to reduce their greenhouse gas emissions. The incentive is often a hard economic one (e.g. a carbon tax), but it can take softer forms, such as reputational incentives attached to meeting an emissions reduction pledge for a country, local government or a company, or branding incentives derived from environmental labeling (e.g. carbon footprint of products). This scope corresponds to what Ascui and Lovell ${ }^{2}$ refer to as the 'market-enabling' frame for carbon accounting, although this largely overlap with the 'political frame' when jurisdictions such as countries or cities are the object of the carbon pricing and/or management mechanism (CPM).

Fifteen schemes are reviewed here (Table 1). The selection criteria were primarily designed to cover the most important existing CPMs. The importance of each scheme was assessed in terms of number of entities concerned, amount of emissions concerned, longevity of the scheme, amount of money at

\footnotetext{
${ }^{a}$ INRA, UMR 1041 CESAER, 21079 Dijon, France.

${ }^{\mathrm{b}}$ CDC Climat, 75009 Paris, France.

${ }^{\mathrm{c}}$ National Physical Laboratory, TW11 OLW Teddington, United Kingdom.

${ }^{d}$ Centre interprofessionnel technique d'études de la pollution atmosphérique (Citepa), 75010 Paris, France.

${ }^{\mathrm{e}}$ South Pole Carbon, Beijing, China.
} 
stake, etc. Priority was given to compliance schemes; that is, schemes designed by a regulator who issues clear and mandatory guidelines and who has some means of enforcing the guidelines. This unique set of guidelines allows us to state what are the existing MRV requirements rather than describe how some entities proceed in terms of MRV within a flurry of different approaches. Within the schemes of lesser importance, priority was given to those which presented an original feature (e.g. the inclusion of the waste sector in the Australian carbon pricing mechanism). Forty-one systematic questions were asked for each scheme (see supplementary materials), and the relevant literature - peer-reviewed articles, reports, regulatory texts, regulatory impact assessment, and so on - was reviewed to help provide answers. In the tables and figures, project scale CPMs are grouped or duplicated by type (e.g. $\mathrm{N}_{2} \mathrm{O}$ emissions in agriculture) which is why the number of categories do not always add up to fifteen.

\section{Definitions}

Monitoring covers the scientific part of the MRV process. It involves getting a number for each variable part of the equation which results in the emissions estimate. This ranges from direct measurement of gas concentration using gas meters to the recording of proxies such as fuel consumption based on the bills of a given entity. The use of proxies is common practice, through the general equation:

activity data $\mathrm{x}$ emission factor $=$ greenhouse gas emissions $($ Eq. 1$)$

where activity data is the proxy (eg. fuel consumption, heads of cattle) and emission factor is the conversion factor (eg. tons of $\mathrm{CO}_{2}$ per liter of burnt fuel, tons of $\mathrm{CO}_{2} \mathrm{e}$ per animal per year). Both activity data and emission factor change over time and hence need to be monitored. Activity data nevertheless tends to vary more frequently than emission factors.

Reporting covers the administrative part of the process. It involves aggregating and recording the numbers, explaining how you came up with them in the requested format, and communicating the results to the relevant authority, such as the regulator or the top management of the company.

The purpose of verification is to detect errors resulting from either innocent mistakes or fraudulent reporting. It is usually conducted by a party not involved in monitoring and reporting who checks that these two steps were conducted in compliance with the relevant guidelines.

\section{MRV scale}

Although not plentiful, the existing literature on MRV in climate economics agrees on three possible scales which greatly influence how MRV can be conducted: territory, entity and project ${ }^{3-5}$.

The territorial scale includes all emissions occurring within a given geographic area such as a country or an administrative region. All activities and entities operating within the area are considered. Examples include national greenhouse gas inventories supervised by the United Nations, regions or cities which have committed to a voluntary or statutory cap on emissions, and jurisdictions engaged in a program for Reducing Emissions from Deforestation, forest Degradation and other changes in forest carbon stocks (REDD+). Although the last example is restricted to forest-related emissions, it still includes all those occurring within the jurisdiction, no matter the activity or entity responsible for them.

The entity scale includes emissions related to the operations of a given public or private entity. In a few cases, all the emissions of the entity are included, such as businesses participating to the Carbon Disclosure Project or entities mandatorily reporting their emissions under the 'Grenelle 2' French 
environmental law enacted in 2010. Most often however, only the emissions corresponding to a restricted set of operations are included. This is the case of mechanisms putting an explicit price on carbon such as the European Union Emissions Trading System, the Australian carbon tax or the Californian Emissions Trading Scheme. In those cases, the MRV occurs at the scale of individual facilities.

The project scale includes emissions stemming from specific emissions reduction projects. These projects are often focused on a given activity, such as destroying an industrial gas or spreading efficient cookstoves. The number of entities and the geographic area considered is then adapted $a d$ hoc to the considered activity. The main example is offset projects, be they certified by the dominant Clean Development Mechanism of the United Nations, or by other standards such as the Verified Carbon Standard or the Gold Standard. As opposed to the two other scales, the MRV of greenhouse gas emissions always comes together with the MRV of greenhouse gas emissions reduction at the project scale: both the project emissions and its counter-factual - or baseline - emissions are monitored, reported and verified at the same time, and along the same rules.

\section{Dealing with uncertainty}

The last important concept for this review is the uncertainty associated with emissions MRV. This concept involves a flurry of terms which are not always understood in the same manner. We adopt the terminology of the IPCC ${ }^{6}$ : uncertainty corresponds to the difference between the estimate and the actual value. Hence, it covers the two types of errors that are commonly distinguished: systematic errors or bias that decrease the accuracy of the estimate (e.g. miscalibrated gas meter, unit error in the reporting) and random errors which decrease the precision of the estimate (e.g. sampling error, errors of copy in the reporting). In monitoring, lack of precision and accuracy can both lead to uncertain estimates but only the first can be dealt with by increasing the number of samples. Bias can only be reduced by monitoring and reporting the same source of emissions with a change in the method. In reporting, both types of errors can be reduced through quality control and verification.

\section{MRV trade-offs}

Scale and uncertainty lead to the two necessary trade-offs in the MRV of greenhouse gas emissions, as explained by Cochran ${ }^{3}$ : cost vs uncertainty and information relevance vs comparability. The tradeoff between cost and uncertainty is one of the key threads of this review. For each CPM considered, we identify whether flexibility provisions are in place to adapt uncertainty requirements to the cost incurred by stakeholders. These provisions may take the form of de minimis thresholds, that is threshold levels of emissions under which monitoring and reporting are not required, or 'materiality thresholds', that is threshold levels of errors under which errors are tolerated during verification. They can also take a more continuous form, for example by increasing the cost of compliance or discounting the benefits from carbon credits in proportion to the uncertainty of monitoring.

The second trade-off between information relevance and comparability comes from the difference in information needs from case to case. A country with only a couple of trees such as Monaco will see the quantification of emissions from its forestry sector as a complete waste of resources when it comes to designing climate mitigation policies. But Canada or Brazil may not see it that way. However, letting each country choose the sources it monitors, the method it uses to report them and the format under which all this is reported would greatly hamper the comparison of emission levels between countries. The same goes for cities, companies and offset projects depending on their specific context and needs.

In a nutshell, five cross-cutting questions are asked on the schemes being reviewed:

(1) what are the requirements pertaining to monitoring uncertainty?

(2) What are the costs for entities to meet these requirements? 
(3) Is a flexible trade-off between requirements and costs allowed?

131 (4) Is requirements stringency adapted to the amount of emissions at stake (materiality)?

132 (5) What balance between comparability and information relevance?

\section{MRV requirements across schemes}

The first cross-cutting question - what are the MRV requirements? - is too large to be answered in a synthetic way. This section thus focuses on two components of this question that have a major impact on MRV costs: requirements pertaining to third-party verification and those pertaining to monitoring uncertainty.

\section{Verification requirements are broadly similar across the board.}

Most CPMs impose a verification of the reports by an independent third-party. Verification requirements are broadly similar across CPMs (Figure 1 ):

first, the third party must be accredited by the regulator for GHG emissions audits and this accreditation tends to be sector-specific;

second, the third party must assess whether the methods used and the reporting format comply with the relevant guidelines;

third, the third party must assess the accuracy, i.e. the absence of bias, of the reported figures;

fourth, the regulator is allowed to question the opinion of the auditor, but seldom does so;

and fifth, the third party tends to be paid directly by the verified entity. Although this creates a potential conflict of interest, the risk of losing the accreditation is a much stronger incentive and keeps auditors from being complacent with their client ${ }^{7}$. Random verification of a few entities only as is the case for small projects under the Gold Standard and for small installations under the Australian Carbon Pricing Mechanism - is an exception: the auditor is then paid by the regulator. The verification of national GHG inventories under the UNFCCC is also not directly paid by the countries under review.

Some details may differ (Table S1). Verification frequency is one example: it tends to be annual for most entities at site/company scale whereas it is variable - up to the project proponent - at project scale. The emphasis put on individuals also varies across schemes: UNFCCC accredited reviewers act in their own name, and so do auditors in California and Australia. Under the EU ETS and the CDM however, it is firms rather than individuals which are accredited, although one of the key criteria to obtain accreditation is of course to secure individual competence either internally or through longterm subcontracting. Note that Member States have some leeway on the accreditation procedures for EU ETS verification. As a result, and although most countries accredit firms, some accredit individuals.

The only schemes which stray away from these general observations are the schemes with little financial stakes: sub-national inventories and company level footprints. The latter are nevertheless often verified: verification is incited under the Carbon Disclosure Project - verified respondents get a higher score within their transparency rating - and it is even mandatory for some companies under the French Grenelle II law (Article 225). Yet these verifications are peculiar: what matters are the reporting procedures of the company - do they ensure the internal consistency and "fairness" of the reported figures - rather than the accuracy and precision of the reported figures. In addition, the requirements on the expertise of the third party on GHG emissions is rather limited in these schemes: indeed, companies tend to use their financial auditors, which saves time as they are already familiar with the company structure and its accounts. 
Sources of monitoring uncertainty are multiple. When calculation methods are used, there are as many sources of uncertainty as there are variables and parameters used in the calculation. Methods exist to combine the uncertainty from all sources in order to produce a comprehensive estimate (see for example GHG Protocol ${ }^{8}$ or IPCC $^{6}$ ). Yet, CPMs seldom set a requirement on the overall uncertainty of a given source. The case of direct measurement in the EU ETS is a notable exception. The EU ETS and a few offset project methodologies get close, as quantitative requirements are set on most sources of uncertainty - activity data and emission factors - involved in the calculation method. Most schemes also require a minimum calibration frequency when instruments are used. This frequency is often borrowed from existing national or international standards. The impact of calibration requirements on the actual uncertainty may be significant but is difficult to quantify across sectors and schemes ${ }^{9}$.

However, the majority of CPMs only set quantitative requirements on a few sources of uncertainty (Figure 2, Table S2). When financial stakes are low - that is when mechanisms are primarily about accounting and tracking rather than directly pricing carbon, as in most jurisdictional schemes or for company-level footprint, the requirements are either qualitative - e.g. using a context-specific emission factor for major sources - or non-existent. Hence, most CPMs only exert a partial control over the uncertainty that is reported.

\section{Incentives to reduce monitoring uncertainty}

\section{Conservativeness: gap between principle and practice.}

MRV concepts and principles are often presented without significant attention to how they are applied in practice. Conservativeness perfectly illustrates this gap between theory and practice.

'Conservativeness' means that when the data is uncertain, a conservative value should be used so that emissions are not underestimated. This principle is often interpreted as an incentive to reduce monitoring uncertainty, often by adding one or two standard deviations to the estimate. If it were so, conservativeness would indeed provide an implicit incentive to reduce uncertainty.

But in practice, most of the rules in CPMs do not discourage the use of default values or the uncertainty of the monitoring method (Table S2). For example, the UNFCCC guidelines for national GHG inventories allow for any type of uncertainty range, provided that the estimate is not biased ${ }^{6}$. The EU ETS limits the uncertainty of some elements but does not reward further uncertainty reduction as long as the threshold is met ${ }^{10}$.

The CDM Executive Board has yet to clarify and systematize its application of the conservativeness principle, except in the case of surveys and samples ${ }^{11}$. Although some CDM tools and methodologies are already awarding fewer credits in proportion to reported uncertainty, this is not systematic. Many CDM methodologies provide an implicit incentive to reduce uncertainty by using conservative default values for some parameters or variables ${ }^{9}$. Yet, these incentives remain limited in the CDM for three reasons ${ }^{12}$ :

(1) in most cases, conservativeness only concerns one or two parameters whereas the number of parameters involved in the calculation often exceeds $\operatorname{ten}^{13}$. These parameters were possibly chosen during the validation of the methodology as the most influential ones based on expert judgment. But this leaves out many sources of uncertainty whose importance has not been assessed in a systematic manner;

(2) conservativeness is only applied to the most uncertain option out of three or four possible monitoring methods (e.g. UNFCCC ${ }^{14}$ );

and (3), an alternative method to the conservative default value is not systematically offered in the 
uncertainty will have to appeal to the Methodology Panel to revise the methodology. The resources time and technical - necessary to undertake such a step represent a significant barrier.

\section{Conservativeness is not a panacea.}

Nevertheless, there may be good reasons not to be conservative when monitoring emissions. One is that conservativeness gives a competitive advantage to larger installations or entities where economies of scale make it economically feasible to use fewer default values and more precise monitoring methods (see Section 4.4). In the EU ETS, this would exacerbate the distortion created by MRV costs and likely explains why the regulator has abstained from embedding conservativeness in the Monitoring and Reporting Regulation (MRR). In California, the default emission factor applied to imported electricity is rather generous: it corresponds to a clean gas power plant ${ }^{15}$. This is the very contrary of being conservative, but it was likely necessary to avoid judicial proceedings from neighbouring states for breaching the constitutional right to free interstate commerce ${ }^{16}$. The EU faced a similar dilemma when setting an emission factor to oil produced from Canadian tar sands under the Fuel Quality Directive ${ }^{17}$. In offset schemes however, the risk of adverse selection ${ }^{20}$ offers a strong argument in favour of conservativeness.

\section{Should there always be an incentive to reduce uncertainty?}

Although generally rare, incentives to reduce monitoring uncertainty are embedded in a few number of CPMs (Figure 3, Table S3). Some offset project methodologies for example discount the amount of credits issued in proportion to the overall monitoring uncertainty (e.g. VCS VM012 on improved forest management ${ }^{18}$ ) or in proportion to the uncertainty of one component of the estimate (e.g. leak flow rate in CDM AM0023 on fugitive emissions ${ }^{19}$ ).

These provisions may make sense in offset schemes which are vulnerable to adverse selection ${ }^{20}$ : project proponents who benefit from the error - because their monitored emissions reductions are by chance above the true value - are more likely to join than those whose emissions reductions are underestimated. This selection bias eventually produces on overestimate in the aggregated total, despite the random nature of each individual error.

However, economic theory and literature do not provide unconditional support for incentives to reduce uncertainty ${ }^{21}$. In general, uncertainties tend to balance out rapidly with an increasing number of emission sources and therefore tend to be of little concern. Exceptions may emerge in specific cases of information asymmetry or when a scheme encompasses only a few large sources.

Indeed, the regulator should in theory worry more about bias than about precision. And in many configurations reducing the reported uncertainty does not reduce the risk of bias. To reduce the risk of bias, the expert judgment of independent and competent auditors likely remains the best suited approach. A likely costly alternative would be to require a second estimate obtained from a different and independent method.

In practice, there is no clear consensus among regulators on the importance of monitoring uncertainty. The European Commission cites the large uncertainty of waste emissions as one of the main reasons to keep the sector outside the EU ETS ${ }^{22}$ whereas it did not visibly hinder Australia from including it in its CPM. Based on economic theory and the existing literature on this topic alone, it is not possible to clearly determine "who made the best choice".

\section{Economies of scale}

Economies of scale are the dominant feature of MRV costs, at least when these costs are compared on a per ton of $\mathrm{CO}_{2} e$ basis. These economies have an automatic component: the division of a given cost by a larger denominator; and an intended one: regulation, mandatorily applied to a large number of sources and entities, must not impose too heavy a burden on the complying entities as these cannot opt-out. 
The larger and the more comprehensive a scheme, the lower the MRV costs. Jurisdictional schemes tend to cover all sources within a jurisdiction which adds up to a large amount of GHG emissions. As a result, they exhibit much lower MRV costs than other schemes per $\mathrm{tCO}_{2} \mathrm{e}$ (Table 1).

However, even when the amount of emissions per entity is comparable, for example between capand-trade schemes and offset schemes, comprehensiveness pushes MRV costs down (Figure 1, Table 1). Indeed, company/site scale schemes tend to be mandatory and therefore to cover all entities that meet the inclusion thresholds (e.g. more than $20 \mathrm{MW}$ for combustion installations under the EU ETS). As such, they must be especially careful with the costs they impose on regulated entities as these may distort the market (e.g. by putting higher costs on smaller entities) or even put unbearable burden on some firms ${ }^{9}$. Conversely, offset schemes in which participation is voluntary cannot bankrupt participating companies through MRV costs: if they are too high, companies simply do not participate. In addition, one of the interests of running an offset scheme is to reveal information on abatement opportunities, monitoring techniques and $\operatorname{costs}^{23,24}$. In this context, there is a rationale for leaning towards higher MRV costs in order to obtain better information. This is likely why offset schemes tend to exhibit higher MRV costs than cap-and-trade schemes (Table 1).

\section{1}

282

283

284

285

286

287

288

289

290

291

292

293

294

295

296

297

298

299

300

301

302

303

304

305

306

307

308

\section{9}

310

311

\section{MRV costs decrease with size.}

Even within the same scheme, MRV costs vary widely. A major factor explaining this variation is the size of entities (Figure 1). Indeed, fixed costs or costs that increase only slowly with entity size are numerous within MRV costs. Most monitoring and reporting costs are insensitive to size: a single monitoring report, methodology, project design document, national inventory report, etc. is needed per entity, no matter the amount it emits or reduces. In monitoring, the costs of a meter do not necessarily increase with the amount of material - electricity, fuel, gas, ... - that it measures. Similarly, sampling costs only increase in proportion to the square root of the sampled population. The same goes for verification: a large part of the workload is proportional to the amount of documentation provided, which is largely independent of the amount of emissions at stake.

After entity size, entity and sector complexity also plays into MRV costs ${ }^{25}$. A large refinery with hundreds of pipes, connections and gas streams is more difficult to MRV than a simple power plant with a couple of boilers. Similarly, two thirds of emissions from cement manufacture usually come from decarbonation. The monitoring of these process emissions involve a complex mass balance approach in addition to the more common and straightforward activity data ${ }^{*}$ emission factor approach used for energy consumption (the remaining third). Across schemes such as the EU ETS, the US EPA GHG Reporting Rule or the Californian ETS, refineries and cement factories face higher MRV costs: although cement factories are large and benefit from the aforementioned economies of scale, their monitoring costs under the US EPA GHG Reporting Rule are two times higher than the overall average on a per $\mathrm{tCO}_{2} e$ basis ${ }^{26}$. Other types of industries are also impacted by their complexity such as electricity importers.

\section{The share of verification costs}

Contrary to conventional wisdom, verification is usually not the main part of MRV costs. On average, it varies between 0 and $50 \%$ of total MRV costs, with most schemes around $25 \%$ (Table 1 ). Verification costs are, however, mostly fixed costs. For smaller sources or entities, it can therefore take the lion's share of MRV costs, up to $80 \%$ of the total ${ }^{25}$. Moreover, to the contrary of monitoring and reporting costs, they cannot be internalized as the auditor must be an independent third party in most schemes.

\section{Materiality is commonly practiced but it does not outweigh economies of scale.}

Materiality is a concept which comes from the audit industry: an auditor should focus on the riskiest parts of what is being audited. In other words, one should pay more attention to larger numbers than 
to smaller ones. Materiality has made its way into the verification procedures of most existing CPMs: accredited auditors can only invalidate a monitoring report when errors exceed a given threshold (e.g. 5\% of total facility emissions in the Californian Emissions Trading Scheme). Nevertheless, the concept of materiality is not taken into account in most jurisdictional schemes, either because verification does not take place - as is the case for most sub-national inventories; or because the guidelines do not contain materiality provisions - which used to be the case for national GHG inventories (Figure 5, Table S4).

The concept of materiality could be extended beyond verification to monitoring and reporting: fewer resources should be spent on smaller sources than on larger sources, or on smaller facilities than on larger facilities. Many provisions exist in carbon markets and carbon taxes to balance stringency with the amount of emissions at stake: smaller facilities are usually not covered by the scheme, and even within the scheme, the uncertainty requirements or the reporting frequency is more lenient for these installations (Table S4). Yet, these provisions do not result in a level playing field. Economies of scale have the upper hand and larger facilities and offset projects end up with lower MRV costs per $\mathrm{tCO}_{2} \mathrm{e}$ (see Section 4.2). Finally, national GHG inventories still largely ignore the concept: the requirements are almost as stringent for Slovenia as they are for Germany. This is not to say that the existing "monitoring materiality" provisions are not useful: inclusion thresholds in particular are fundamental in limiting costs. The US EPA ${ }^{26}$ assessed the effectiveness of a minimum threshold for inclusion in the perimeter of the regulation. Compared to $25,000 \mathrm{tCO}_{2} \mathrm{e} \mathrm{yr}^{-1}$ threshold retained in the US, a 10,000 $\mathrm{tCO}_{2} \mathrm{e} \mathrm{yr}^{-1}$ threshold would increase costs by $35 \%$ and cover only $1 \%$ more emissions. Conversely, decreasing the inclusion threshold to $100,000 \mathrm{tCO}_{2} \mathrm{e} \mathrm{yr}^{-1}$ would save $23 \%$ of the costs and cover $2.5 \%$ fewer emissions.

\section{Comparability often trumps information relevance}

Comparability between entities reporting within the same CPM is usually a top priority. As a result, most mechanisms offer little leeway in terms of scope, level of source disaggregation and even monitoring method.

Scope and level of source disaggregation. All ETSs, taxes and offset projects define very precisely the gases and sources of emissions that are monitored. They also specify a common reporting format with a fixed separation of emissions sources. No leeway is left to the agent to adapt the scope or level of disaggregation to its own needs/constraints.

Monitoring method. ETSs, taxes and offset projects are very restrictive in terms of monitoring methods. Although a choice is usually offered to the agent, it is limited to a few options for which instruments and emissions factors are explicitly listed.

Schemes and management systems with limited constraints or financial stakes such as sub-national inventories and company-level footprint are the notable exceptions. Sub-national inventories follow a variety of guidelines, and the guidelines themselves are limited to accounting principles and suggested emissions factors. Each entity is then free to choose, within the guidelines or elsewhere, the detailed equations, monitored variables and instruments which best suits its needs and constraints. These entities are usually undertaking their MRV as a means to assess the effectiveness of their internal mitigation strategy. They therefore extensively use the large leeway offered by the relevant MRV guidelines to adapt the MRV procedures so that it suits their specific needs. Cochran ${ }^{3}$ illustrates this phenomenon with the GHG inventories of cities. For company-level footprint, the trade-off is a little more balanced: the possibility for outsiders to compare companies between one another and the repeated use of the same consultants within a sector to put together company-level footprints tend to foster comparability on scope 1 - site-level emissions - and scope 2 - electricity use. For scope 3 - upstream and downstream emissions - however, company-level footprints remain very heterogeneous. 
National greenhouse gas inventories under the UNFCCC lie somewhat in the middle. Countries must use a very strict reporting format which makes comparison easy. But the choice on monitoring methods is almost unlimited as countries are always offered the possibility to use a "Tier 3 " method. "Tier 3" tends to be whatever model the country proposes as long as some general criteria - e.g. the model has been validated and published in the peer-reviewed literature - are met. Use of tier 3 is fairly uncommon given that even lower tiers already offer significant leeway concerning acceptable activity data and emission factors. As a result, reported figures are not strictly comparable between countries, although verification, and in particular the use of comparison tools provided by the UNFCCC Secretariat, keeps heterogeneity within acceptable limits.

\section{Conclusion}

Regarding our five cross-cutting questions, one can conclude that conventional wisdom on MRV is not often promoted in existing CPMs. One would intuitively encourage quantitative requirements on emissions uncertainty, together with an incentive to improve precision. Most often, this is only partially applied, if at all. Further, the time and resources spent on small sources of emissions would be expected to be limited. While this kind of 'materiality' is widespread, the softened rules for smaller sources are largely outweighed by economies of scale: in all schemes, MRV costs per ton are primarily driven by the size of the source. This is not to say that existing MRV rules are ill-devised. First, conventional wisdom may be wrong. Economic models indeed struggle to justify the usefulness of incentives to reduce monitoring uncertainty when dealing with many, small sources. Second, some phenomena, such as economies of scale, may be beyond the control of the regulator. MRV rules which create no market distortion are likely an unreachable grail.

These conclusions should be of great use to the scientific and industrial community currently designing new GHG monitoring technologies for use in existing CPMs:

(1) in most cases, there is no point in developing technologies with lower uncertainty than current practices because the rules do not value reduced uncertainty. In particular, the so-called 'conservativeness' principle often invoked to demonstrate the economic value of improved monitoring techniques is specific to a subset of CPMs - offset projects - and is not even applied systematically and consistently there;

(2) a more promising outcome awaits technologies which would meet the uncertainty requirements at a lower cost than what is achieved by current practices. The figures provided in this review on maximum uncertainty thresholds and MRV costs can be used as benchmarks by technology developers; and

(3) an alternative could be to lobby regulators for regulations with more comprehensive and more direct incentives to reduce monitoring uncertainty. This would likely be perilous as top-down regulations change slowly, in particular when there is no obvious rationale for the regulator to reduce monitoring uncertainty (see sections 3.2 and 3.3). Bottom-up CPMs such as offset projects are easier to amend, but their market size plummeted during the second half of 2012 without any clear prospect of recovery ${ }^{27}$.

Another cross-cutting conclusion to this study is that MRV rules significantly differ not only between "scales", but also within them: the EU, Australia, California and Shenzhen have set different MRV rules in their respective site-level CPMs. Five thousand sites with emissions lower than $25,000 \mathrm{tCO}_{2} \mathrm{e}$ per year are MRVed under the EU ETS while verification is only mandatory for sites emitting over $125,000 \mathrm{tCO}_{2} \mathrm{e}$ in Australia. The scope of the EU ETS is limited to heat and power generation and some industrial processes while the transportation sector, imported electricity, and waste are included in some of the other schemes. Shenzhen even double-counts emissions from electricity.

Will these MRV differences lock the world into incompatible frameworks with different carbon prices? Not necessarily. When considering whether to link two CPMs, mutual confidence in their 
respective level of ambition will likely be pivotal for the regulators involved. And this confidence can be obtained with reliable MRV procedures on both sides even if they are not strictly equivalent. Only time will tell.

\section{References}

1. Bellassen, V. \& Stephan, N. (eds), Accounting for Carbon: Monitoring, Reporting and Verifying Emissions in the Climate Economy. (Cambridge University Press, 2015).

2. Ascui, F. \& Lovell, H. As frames collide: making sense of carbon accounting. Accounting, Auditing \& Accountability Journal 24, 978-999 (2011).

3. Cochran, I. A Use-Based Analysis of Local-Scale GHG Inventories. 37 p (CDC Climat Research, 2010).

4. IGES. Measurement, Reporting and Verification (MRV) for low carbon development: Learning from experience in Asia. 136 p (IGES, 2012).

5. Ninomiya, Y. Classification of MRV of GHG Emissions/Reductions: for the discussions on NAMAs and MRV. 10 (IGES, 2012).

6. IPCC. 2006 IPCC guidelines for national greenhouse gas inventories. (IGES, 2006).

7. Cormier, A. \& Bellassen, V. The risks of CDM projects: How did only $30 \%$ of expected credits come through? Energy Policy 54, 173-183 (2013).

8. GHG Protocol. GHG Protocol guidance on uncertainty assessment in GHG inventories and calculating statistical parameter uncertainty. $17 \mathrm{p}$ (WRI/WBCSD, 2004).

9. Warnecke, C. Can CDM monitoring requirements be reduced while maintaining environmental integrity? Climate Policy 24 p (2014).

10. European Commission. Commission Regulation (EU) No 601/2012 of 21 June 2012 on the monitoring and reporting of greenhouse gas emissions pursuant to Directive 2003/87/EC of the European Parliament and of the Council. (2012).

11. UNFCCC. Standard for sampling and surveys for cdm project activities - version 3.0. $8 \mathrm{p}(2011)$.

12. Shishlov, I. \& Bellassen, V. Review of monitoring uncertainty requirements in the CDM. 33 p (CDC Climat Research, 2014).

13. Barker, A. \& Robinson, R. Uncertainty in Monitoring of Carbon Offsetting Projects. 50 p (National Physical Laboratory, 2014).

14. UNFCCC. Tool to calculate project or leakage CO2 emissions from fossil fuel combustion. 8 p (2008).

15. California Air Resource Board. ARB Mandatory Reporting Regulation. California Code of Regulations Title 17, CCR, sections 95100 - 95158, (2013).

16. Cosbey, A. et al. A Guide for the Concerned: Guidance on the elaboration and implementation of border carbon adjustment. 24 p (Entwined, 2012).

17. Kokoni, S. \& Skea, J. Input-output and life-cycle emissions accounting: applications in the real world. Climate Policy 14, 372-396 (2014). 
18. VCS. VM0012 Improved Forest Management in Temperate and Boreal Forests (LtPF) - Version 1.1. 83 p (Verified Carbon Standard, 2012).

19. UNFCCC. Approved baseline and monitoring methodology AM0023 - Leak detection and repair in gas production, processing, transmission, storage and distribution systems and in refinery facilities - Version 04.0.0. 21 p (2011).

20. Millard-Ball, A. The trouble with voluntary emissions trading: Uncertainty and adverse selection in sectoral crediting programs. Journal of Environmental Economics and Management 65, 40-55 (2013).

21. Shishlov, I. MRV incentives: theory and practice (the CDM experience). (2014).

22. European Commission. Inclusion of additional activities and gases into the EUemissions trading scheme. (European Commission, Directorate General for Environment, 2006).

23. Bellassen, V. \& Alberola, E. European Offset Projects: A tool to rally Poland towards the 2030 Energy Climate Package. Tendances Carbone 1 (2014).

24. Shishlov, I., Bellassen, V. \& Leguet, B. Joint Implementation: a frontier mechanism within the borders of an emissions cap. 40 p (CDC Climat Research, 2012).

25. King, K., Pye, S. \& Davison, S. Assessing the cost to UK operators of compliance with the EU Emissions Trading System. 31 p (Aether, 2010).

26. US EPA. Regulatory Impact Analysis for the Mandatory Reporting of Greenhouse Gas Emissions Final Rule (GHG Reporting). 213 p (United States Environmental Protection Agency, 2009).

27. Stephan, N., Bellassen, V. \& Alberola, E. Use of Kyoto credits by European industrial installations: from an efficient market to a burst bubble. $24 \mathrm{p}$ (CDC Climat Research, 2014).

28. Hogan, P. et al. Tracking Emissions and Mitigation Actions: Current Practice in China, Germany, Italy, and the United States. 78 p (Climate Policy Initiative, 2012).

29. Pacala, S. et al. Verifying Greenhouse Gas Emissions: Methods to Support International Climate Agreements Committee on Methods for Estimating Greenhouse Gas Emissions, National Research Council Report. National Academy of Sciences, USA 110 p (2010).

30. UNFCCC. Programme budget for the biennium 2012-2013. 10 p (2012).

31. ABC. Synthèse Enquête Flash 2013. (Association Bilan Carbone, 2013).

32. Beaurain, F. \& Schmidt-Traub, G. Developing CDM Programmes of Activities: a Guidebook. 75 p (South Pole Carbon Asset Management Ltd., 2010).

33. Chenost, C. \& Gardette, Y-M. Bringing forest carbon projects to the market. (UNEP, 2010).

34. Guigon, P., Bellassen, V. \& Ambrosi, P. Voluntary Carbon Markets: What the Standards Say... 46 p (CDC Climat Research, 2009).

35. Hardcastle, P. D. \& Baird, D. Capability and cost assessment of the major forest nations to measure and monitor their forest carbon. (Office of Climate Change, 2008). 
36. Krey, M. Transaction costs of unilateral CDM projects in India-results from an empirical survey. Energy Policy 33, 2385-2397 (2005).

37. Michaelowa, A. \& Stronzik, M. Transaction Costs of the Kyoto Mechanisms. (2002).

38. Plugge, D., Baldauf, T. \& Köhl, M. The global climate change mitigation strategy REDD: monitoring costs and uncertainties jeopardize economic benefits. Climatic Change 119, 247-259 (2013).

39. UNEP. Guidebook to Financing CDM Projects. (2007).

40. Böttcher, H. et al. An assessment of monitoring requirements and costs of 'Reduced Emissions from Deforestation and Degradation'. Carbon Balance and Management 4, 7 (2009).

41. AEA. Costs of Compliance with the EU Emissions Trading Scheme. (UK Environment Agency, 2006).

42. ETG. Administrative Cost of the Emissions Trading Scheme to Participants. $2 \mathrm{p}$ (Emissions Trading Group, 2008).

43. European Commission. Impact assessment - Accompanying the document COMMISSION REGULATION (EU) No .../.. of XXX on the monitoring and reporting of greenhouse gas emissions pursuant to Directive 2003/87/EC of the European Parliament and of the Council and COMMISSION REGULATION (EU) No ..... of $X X X$ on the verification of greenhouse gas emission reports and tonne-kilometre reports and the accreditation of verifiers pursuant to Directive 2003/87/EC of the European Parliament and of the Council. 56 p (2012).

44. European Commission. Impact assessment - Accompanying document to the Proposal for a directive of the European parliament and of the Council amending Directive 2003/87/EC so as to improve and extend the EU greenhouse gas emission allowance trading system. $255 \mathrm{p}(2008)$.

45. Graus, W. \& Voogt, M. Small installations within the EU Emissions Trading Scheme. 32 p (European Commission \& Ecofys, 2007).

46. Jaraité, J., Convery, F. \& Di Maria, C. Transaction costs for firms in the EU ETS: lessons from Ireland. Climate Policy 10, 190-215 (2010).

47. Heindl, P. Transaction costs and tradable permits: Empirical evidence from the EU emissions trading scheme. (ZEW (Center for European Economic Research), 2012).

48. DIICCSRTE. National Inventory Report 2011. (Department of Industry, Innovation, Climate Change, Science, Research and Tertiary Education, 2013).

49. House of Representatives. National Greenhouse and Energy Reporting Bill, Explanatory Memorandum. (2007).

50. Ministry of Finance. Australia's plan for clean energy future. (2011).

51. ARB. Initial Statement of Reasons for Rulemaking, amendments to the regulation for the mandatory reporting of greenhouse gas emissions. (California Air Resource Board, 2013).

52. ARB. Initial Statement of Reasons for Rulemaking, amendments to the regulation for the mandatory reporting of greenhouse gas emissions and conforming amendments to the definition sections of the $A B 32$ cost of implementation fee regulation and the capand-trade regulation. (California Air Resource Board, 2012). 
53. ARB. Initial Statement of Reasons for Rulemaking, aproposed regulation for mandatory reporting of greenhouse gas emissions pursuant to the Global warming solutions act of 2006. (California Air Resource Board, 2007).

54. ARB. Initial Statement of Reasons for Rulemaking, revisions to the regulation for mandatory reporting of greenhouse gas emissions pursuant to the Global warming solutions act of 2006. (California Air Resource Board, 2010).

55. Price Waterhouse Coopers \& Carbon Disclosure Project. Review of the Contribution of Reporting to GHG Emissions Reductions and Associated Costs and Benefits. $109 \mathrm{p}$ (UK Department for Environment, Food and Rural Affairs, 2007).

56. IGES. One Hundred Questions \& Answers about MRV in Developing Countries. (Institute for Global Environmental Strategies, 2013).

57. Warnecke, C., Klein, N., Perroy, R. \& Tippman, R. CDM Market Support Study. (KFW Bankengruppe, 2013).

58. Cacho, O. J., Wise, R. M. \& MacDicken, K. G. Carbon Monitoring Costs and their Effect on Incentives to Sequester Carbon through Forestry. Mitigation and Adaptation Strategies for Global Change 9, 273-293 (2004).

59. Martel, S. Évaluation préliminaire des coûts de suivi pour un projet en métropole. (2013).

60. Pearson, T. R. H., Brown, S., Sohngen, B., Henman, J. \& Ohrel, S. Transaction costs for carbon sequestration projects in the tropical forest sector. Mitigation and Adaptation Strategies for Global Change (2013).

61. Torres, D. Les méthodes et coûts du suivi pratiqués dans les pays en développement. (2013).

62. Vallejo, A., Chandra, R. R. \& van der Linder, M. Manual for Monitoring of CDM Afforestation and Reforestation Projects - Part I - Standard Operational Procedures. (World Bank, 2011).

63. UNFCCC. Guidelines for the technical review of greenhouse gas inventories from parties included in annex I to the Convention. FCCC/CP/2002/8 (2002).

64. GHG Protocol. The Global Protocol for Community-Scale Greenhouse Gas Emissions - GPC Pilot Version 1.0. 14 p (WRI/WBCSD, 2012).

65. Covenant of Mayors. How to Develop a Sustainable Energy Action Plan. $124 \mathrm{p}$ (2010).

66. ADEME. Bilan Carbone ${ }^{\circledR}$ Entreprises - Collectivités -Territoires. Guide méthodologique - version 6.1 - Objectifs et principes de comptabilisation. $116 \mathrm{p}$ (Agence de l'Environnement et de la Maîtrise de l'Energie, 2010).

67. VCS. JNR Validation and Verification Process, v3.0. 14 p (Verified Carbon Standard, 2013).

68. European Commission. Commission Regulation 600/2012 on the verification of greenhouse gas emission reports and tonne-kilometre reports and the accreditation of verifiers pursuant to Directive 2003/87/EC of the European Parliament and of the Council. (2012).

69. Australian Government. National Greenhouse and Energy Reporting (Measurement), Amendment Determination 2013 (No. 1) - F2013L01191. (2013). 
70. Shenzhen People's Congress. Specification with guidance for quantification and reporting of the organization's greenhouse gas emissions. (2012).

71. Journal Officiel de la République Française. Loi $n^{\circ}$ 2010-788 du 12 juillet 2010 portant engagement national pour l'environnement. (2010).

72. MEDDE. Méthode pour la réalisation des bilans d'émissions de Gaz à effet de serre conformément à l'article 75 de la loi $n^{\circ} 2010-788$ du 12 juillet 2010 portant engagement national pour l'environnement. $46 \mathrm{p}$ (Ministère de l'Ecologie, du Développement Durable et de l'Energie, 2012).

73. CDP. Guidance for companies reporting on climate change on behalf of investors \& supply chain members. 173 p (Carbon Disclosure Project, 2013).

74. UNFCCC. CDM Validation and Verification Standard - Version 03.0. 63 p (2012).

75. CAR. Program Manual. 42 p (Climate Action Reserve, 2011).

76. VCS. VCS Standard. Version 3.32 p (Verified Carbon Standard, 2012).

77. ACR. The American Carbon Registry® Validation and Verification Guideline Version 1.1. 64 p (American Carbon Registry, 2012).

78. Journal Officiel de la République Française. Arrêté du 2 mars 2007 pris pour l'application des articles 3 à 5 du décret $n^{\circ} 2006-622$ du 29 mai 2006 et relatif à l'agrément des activités de projet relevant des articles 6 et 12 du protocole de Kyoto Version consolidée au 02 décembre 2012. (2012).

79. VCS. Jurisdictional and Nested REDD+ (JNR) Requirements - Version 3.1. $57 \mathrm{p}$ (Verified Carbon Standard, 2013).

80. UNFCCC. CDM Project Standard for project design requirements including principles of monitoring - version 6.0. $61 \mathrm{p}$ (2014).

81. CAR. Nitrogen Management - Project Protocol, version 1.1. 138 p (Climate Action Reserve, 2013).

82. VCS. Quantifying N2O Emissions Reductions in Agricultural Crops through Nitrogen Fertilizer Rate Reduction, v1.0. 56 p (Verified Carbon Standard, 2013).

83. ACR. Methodology for quantifying Nitous Oxide (N2O) emissions reductions from reduced use of nitrogen fertilizer on agricultural crops - Version 1. $45 \mathrm{p}$ (American Carbon Registry, 2012).

84. In Vivo. Méthodologie spécifique aux projets de réduction des émissions de N2O dues à la dénitrification des sols agricoles par insertion de légumineuses dans les rotations agricoles. $42 \mathrm{p}$ (2011).

85. UNFCCC. Afforestation and reforestation project activities implemented on lands other than wetlands - Version 03.0. 17 p (2013).

86. UNFCCC. Afforestation and reforesta tion of lands except wetlands - Version 2.0. 15 $\mathrm{p}$ (2013).

87. VCS. VM0010 Methodology for Improved Forest Management: Conversion from Logged to Protected Forest - Version 1.2. 72 p (Verified Carbon Standard, 2013).

Correspondence and requests for materials should be addressed to Valentin Bellassen (corresponding author). 


\section{Acknowledgements}

616 First and foremost, we would like to thank the sponsors of the MRV project, without whom this 617 review would never have been written: Agence Française de Développement; EIT Climate-KIC; 618 Ministère français de l'Agriculture, de l'Agroalimentaire et de la Forêt; Ministère français de 619 I'Ecologie, du Développement Durable et de l'Energie; Union des Industries de la Fertilisation.

620 We are also grateful to the Marco Loprieno (European Commission) and Massamba Thioye (UNFCCC) 621 who accepted to discuss our findings at the Bonn MRV conference in June 2014. We also thank 622 Xueman Wang and Pierre Guigon (Partnership for Market Readiness, The World Bank) for the useful 623 connection provided with new CPMs being developed in emerging economies.

624 Many more people contributed to the book on which this review is based through interviews, 625 comments or reviews. Their contribution is acknowledged in the relevant chapters of the book.

\section{10. Authors contributions}

627 V.B. designed the study, analyzed the pre-processed data and wrote the paper. V.B, M.A., E.A., A.B., 628 J-P.C., C.C., I.C., M.D., C.D., C.F., G.J., R.M., R.R, and I.S. gathered and pre-processed the raw 629 materials. N.S. coordinated data collection. 


\section{Tables}

\section{Table 1. MRV costs across carbon pricing and management mechanisms}

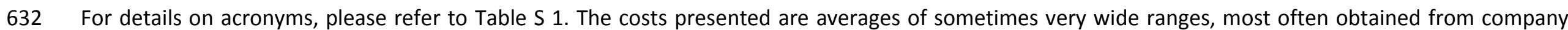
633 surveys or calculations by the regulator in the impact assessment of its regulation. See $\left({ }^{1}\right)$ for details.

\begin{tabular}{|c|c|c|c|c|c|c|}
\hline $\begin{array}{l}\text { MRV } \\
\text { scale }\end{array}$ & & Standard or regulation & Cost per entity $\left(€ \mathrm{yr}^{-1}\right)$ & $\begin{array}{l}\text { Cost per emission } \\
\left(€ t \mathrm{tCO}_{2} \mathrm{e}^{-1}\right)\end{array}$ & $\begin{array}{l}\text { Share of verification in } \\
\text { total MRV costs }\end{array}$ & $\begin{array}{l}\text { Original sources } \\
\text { See for }\left({ }^{1}\right) \text { details on the methods for } \\
\text { each carbon pricing mechanism. }\end{array}$ \\
\hline \multirow{3}{*}{ 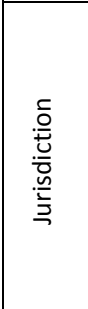 } & National inventories & $\begin{array}{l}\text { United Nations } \text { Framework } \\
\text { Convention on Climate Change } \\
\text { (UNFCCC) }\end{array}$ & 800,000 & 0.02 & $22 \%$ & $1,28-30$ \\
\hline & Sub-national inventories & $\begin{array}{l}\text { Global Protocol for Community- } \\
\text { Scale Greenhouse Gas Emissions } \\
\text { (GPC) / Covenant of mayors (Cm) / } \\
\text { Bilan Carbone Territorial (BCT) }\end{array}$ & 18,500 & 0.003 & $0 \%$ & 31 \\
\hline & Jurisdictional REDD+ & Verified Carbon Standard (VCS) & 145,000 & 0.40 & $24 \%$ & $32-40$ \\
\hline \multirow{5}{*}{ 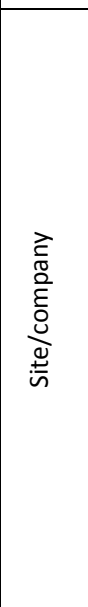 } & EU ETS & $\begin{array}{lrr}\begin{array}{l}\text { Monitoring } \\
\text { Regulation }\end{array} \text { (MRR), } & \text { Reporting } \\
\text { Regulation (VR) } & \end{array}$ & 22,000 & 0.07 & $40 \%$ & $25,26,41-47$ \\
\hline & Landfills in the Australian CPM & $\begin{array}{l}\text { National Greenhouse and Energy } \\
\text { Reporting Act (NGER) }\end{array}$ & (M\&R only) & 0.22 & $64 \%$ & $48-50$ \\
\hline & $\begin{array}{l}\text { Imported electricity in the } \\
\text { Californian ETS }\end{array}$ & $\begin{array}{|lrr|}\text { Mandatory } & \text { reporting } & \text { of } \\
\text { greenhouse } & \text { gas } & \text { emissions } \\
\text { regulation (MRR) } & \end{array}$ & 73,000 & 0.14 & not available & $51-54$ \\
\hline & Shenzhen ETS & $\begin{array}{l}\text { Specification with guidance for } \\
\text { quantification and reporting of the } \\
\text { organization's greenhouse gas } \\
\text { emissions (SZDB/Z 69) }\end{array}$ & no data & no data & no data & \\
\hline & Company-level footprint & $\begin{array}{l}\text { French Grenelle II law Article } 75 \text { / } \\
\text { French Grenelle II law - Article 225 } \\
\text { / Carbon Disclosure Project (CDP) }\end{array}$ & $77,000^{f}$ & no data & no data & 55 \\
\hline 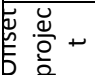 & Projects & $\begin{array}{l}\text { Clean Development Mechanism } \\
\text { (CDM) }\end{array}$ & 55,000 & 0.57 & $32 \%$ & $32,34,36,37,39,56,57$ \\
\hline
\end{tabular}

${ }^{\mathrm{f}}$ Includes the costs of all MRV frameworks used by the surveyed UK quoted companies which in some cases report under the CDP, the EU ETS and the CRC at the same time. 


\begin{tabular}{|c|c|c|c|c|c|c|}
\hline $\begin{array}{l}\text { MRV } \\
\text { scale }\end{array}$ & & Standard or regulation & Cost per entity $\left(€ \mathrm{yr}^{-1}\right)$ & $\begin{array}{l}\text { Cost per emission } \\
\left(€+\mathrm{tCO}_{2} \mathrm{e}^{-1}\right)\end{array}$ & $\begin{array}{l}\text { Share of verification in } \\
\text { total MRV costs }\end{array}$ & $\begin{array}{l}\text { Original sources } \\
\text { See for }\left({ }^{1}\right) \text { details on the methods for } \\
\text { each carbon pricing mechanism. }\end{array}$ \\
\hline & Agricultural $\mathrm{N}_{2} \mathrm{O}$ projects & $\begin{array}{l}\text { Climate Action Reserve (CAR) / VCS } \\
\text { / American Carbon Registry (ACR) / } \\
\text { Joint Implementation (JI) - France }\end{array}$ & no data & no data & no data & \\
\hline & Reforestation projects & CDM & 17,000 & 0.80 & $48 \%$ & $33,58-62$ \\
\hline & Forest management projects & VCS & $\begin{array}{l}\text { Likely similar to CDM } \\
\text { reforestation projects }\end{array}$ & $\begin{array}{l}\text { Likely similar to CDM } \\
\text { reforestation projects }\end{array}$ & $\begin{array}{l}\text { Likely similar to CDM } \\
\text { reforestation projects }\end{array}$ & \\
\hline & Fugitive projects & CDM & 167,000 & 0.22 & $15 \%$ & 1 \\
\hline
\end{tabular}




\section{Figures}

Figure 1. Typology of verification requirements across carbon pricing and management mechanisms (CPMs)

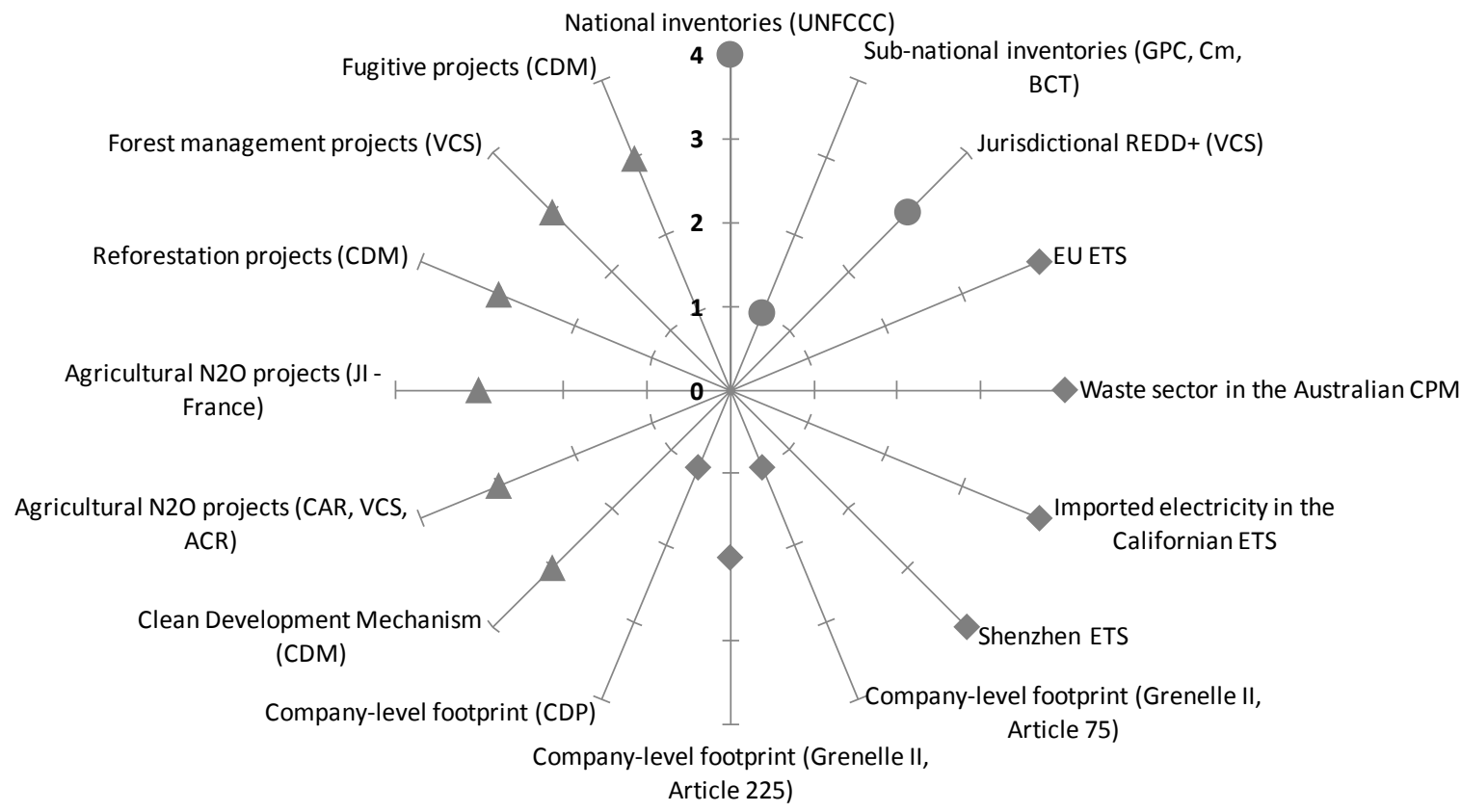

\section{Type of verification requirements}

1 No verification requirements

2 Focused on reporting procedures rather than reported figures

3 Variable frequency, accredited third party

4 Annual frequency, accredited third party

\section{Scale of the CPM}

Jurisdictional scale

Site/company scale

Offset project scale

For a detailed justification of the typology, see Table S1.

Sources: United Nations Framework Convention on Climate Change (UNFCCC) ${ }^{63}$, Global Protocol for Community-Scale Greenhouse Gas Emissions $(\mathrm{GPC})^{64}$, Covenant of mayors $(\mathrm{Cm})^{65}$, Bilan Carbone Territorial $(B C T)^{66}$, Verified Carbon Standard $(\mathrm{VCS})^{67}$, Verification Regulation $(\mathrm{VR})^{68}$, National Greenhouse and Energy Reporting Act (NGER) ${ }^{69}$, Mandatory reporting of greenhouse gas emissions regulation (MRR) $)^{15}$, Specification with guidance for quantification and reporting of the organization's greenhouse gas emissions (SZDB/Z 69) ${ }^{70}$, French Grenelle II law Article $75^{71,72}$, French Grenelle II law Article 225 $5^{71}$, Carbon Disclosure Project $(C D P)^{73}$, Clean Development Mechanism (CDM) ${ }^{74}$, Climate Action Reserve $(\mathrm{CAR})^{75}, \mathrm{VCS}^{76}$, American Carbon Registry (ACR) ${ }^{77}$, Joint Implementation (JI) - France ${ }^{78}$, $\mathrm{CDM}^{74}, \mathrm{VCS}^{76}, \mathrm{CDM}^{74}$. 
Figure 2. Typology of uncertainty requirements across carbon pricing and management mechanisms (CPMs)

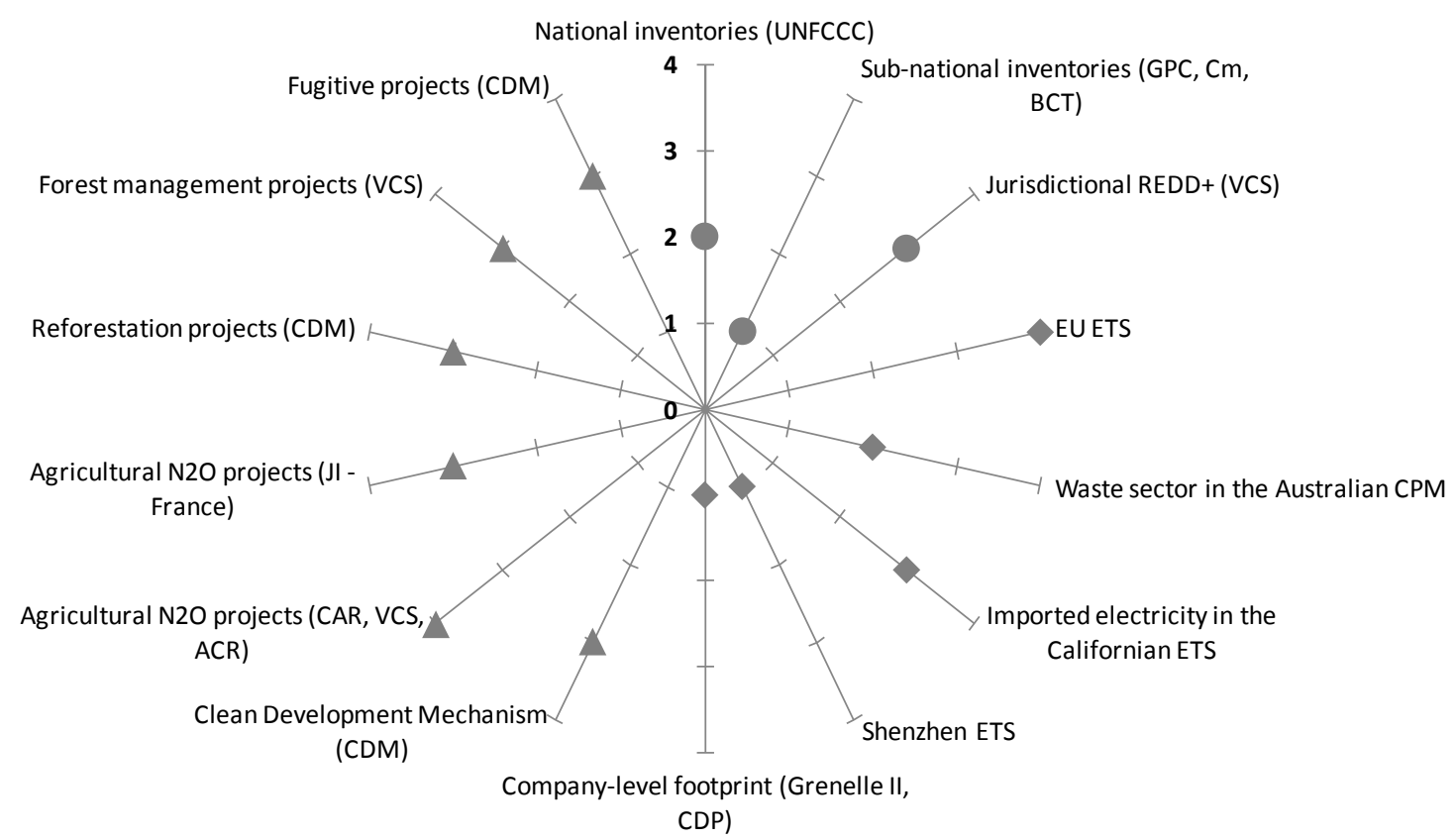

\section{Type of uncertainty requirements}

1 No uncertainty requirements

2 Qualitative (e.g. key categories should use a country-specific emission factor)

3 Quantitative, covering a few sources of uncertainty (e.g. sampling error shall be no greater than $10 \%$ )

4 Quantitative, covering most sources of uncertainty (e.g. total uncertainty shall be no greater than $2.5-10 \%$ )

\section{Scale of the CPM}

Jurisdictional scale

Site/company scale

$\triangle$ Offset project scale

For a detailed justification of the typology, see Table S2.

Sources: UNFCCC ${ }^{6}, \mathrm{GPC}^{64}, \mathrm{Cm}^{65}, \mathrm{BCT}^{66}, \mathrm{VCS}^{79}$, Monitoring and Reporting Regulation (MRR) ${ }^{10}, \mathrm{NGER}^{69}$, $\mathrm{MRR}^{15}, \mathrm{SZDB} / \mathrm{Z} 69^{70}, \mathrm{CDP}^{73}$, Grenelle II Article $225 \& 75^{71,72}, \mathrm{CDM}^{11,80}, \mathrm{CAR}^{81}, \mathrm{VCS}^{82}, \mathrm{ACR}^{83}$, JI - France ${ }^{84}$, $\mathrm{CDM}^{85,86}, \mathrm{VCS}^{18,87}, \mathrm{CDM}^{19}$. 
Figure 3. Typology of incentives to reduce uncertainty across carbon pricing and management mechanisms (CPMs)

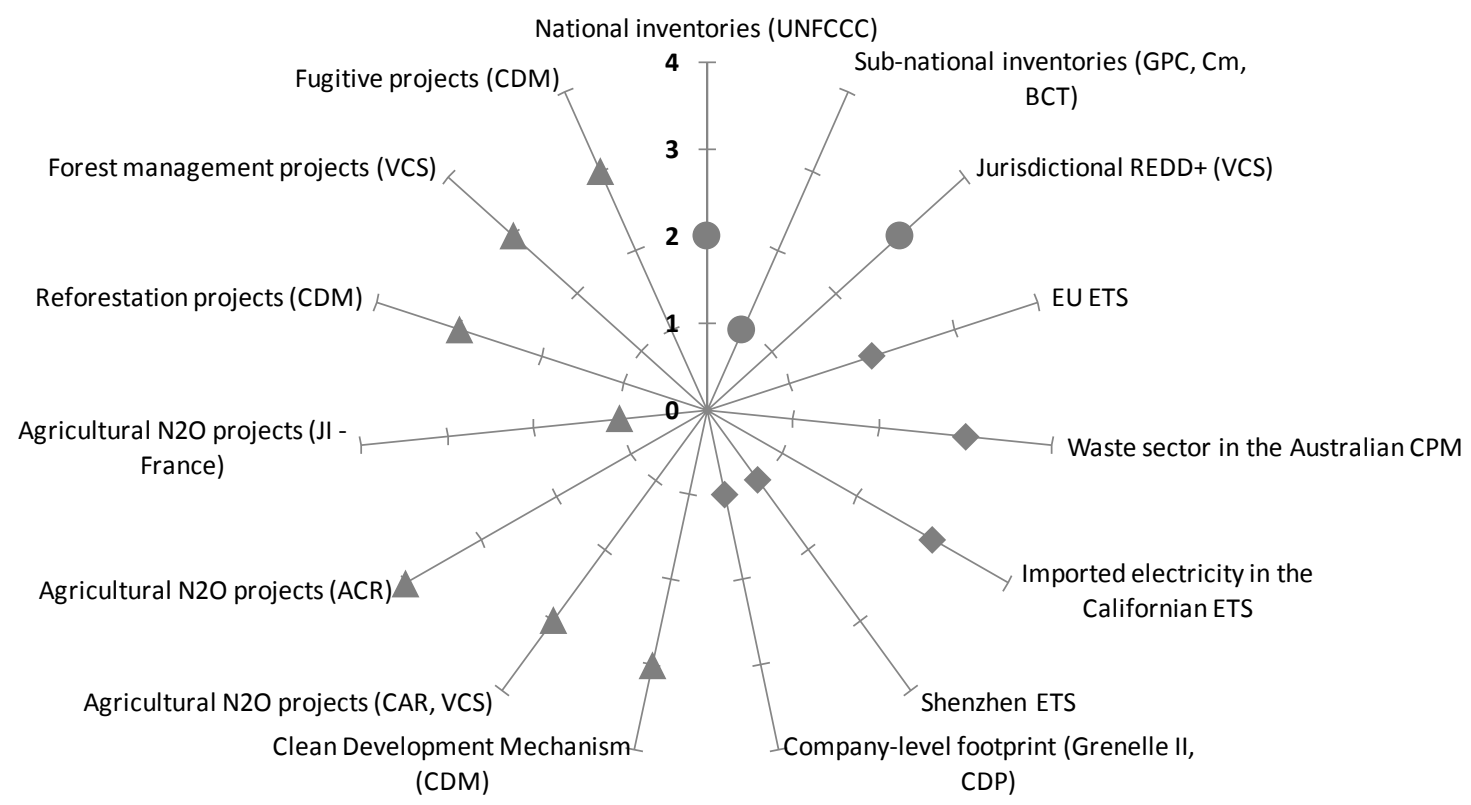

\section{Type of incentive to reduce uncertainty}

\section{None.}

2 Qualitative (e.g. general principle of "continuous improvement").

3 Indirect (e.g. through a conservative emission factor) and quantitative, but covering only a few sources of uncertainty.

4 Direct (e.g. deduction factor) and quantitative, covering most sources of uncertainty.

\section{Scale of the CPM}

Jurisdictional scale

Site/company scale

$\triangle$ Offset project scale

For a detailed justification of the typology, see Table S3.

Sources: UNFCCC $6 \mathrm{GPC}^{64}, \mathrm{Cm}^{65}, \mathrm{BCT}^{66}, \mathrm{VCS}^{79}, \mathrm{MRR}^{10}, \mathrm{NGER}^{69}, \mathrm{MRR}^{15}, \mathrm{SZDB} / \mathrm{Z} 69^{70}, \mathrm{CDP}^{73}$, Grenelle II Article $225 \& 75^{71,72}, \mathrm{CDM}^{80}, \mathrm{CAR}^{81}, \mathrm{VCS}^{82}, \mathrm{ACR}^{83}, \mathrm{JI}^{- \text {France }^{84}}, \mathrm{CDM}^{85,86}, \mathrm{VCS}^{18,87}, \mathrm{CDM}^{19}$.

Figure 4. Economies of scale in MRV 


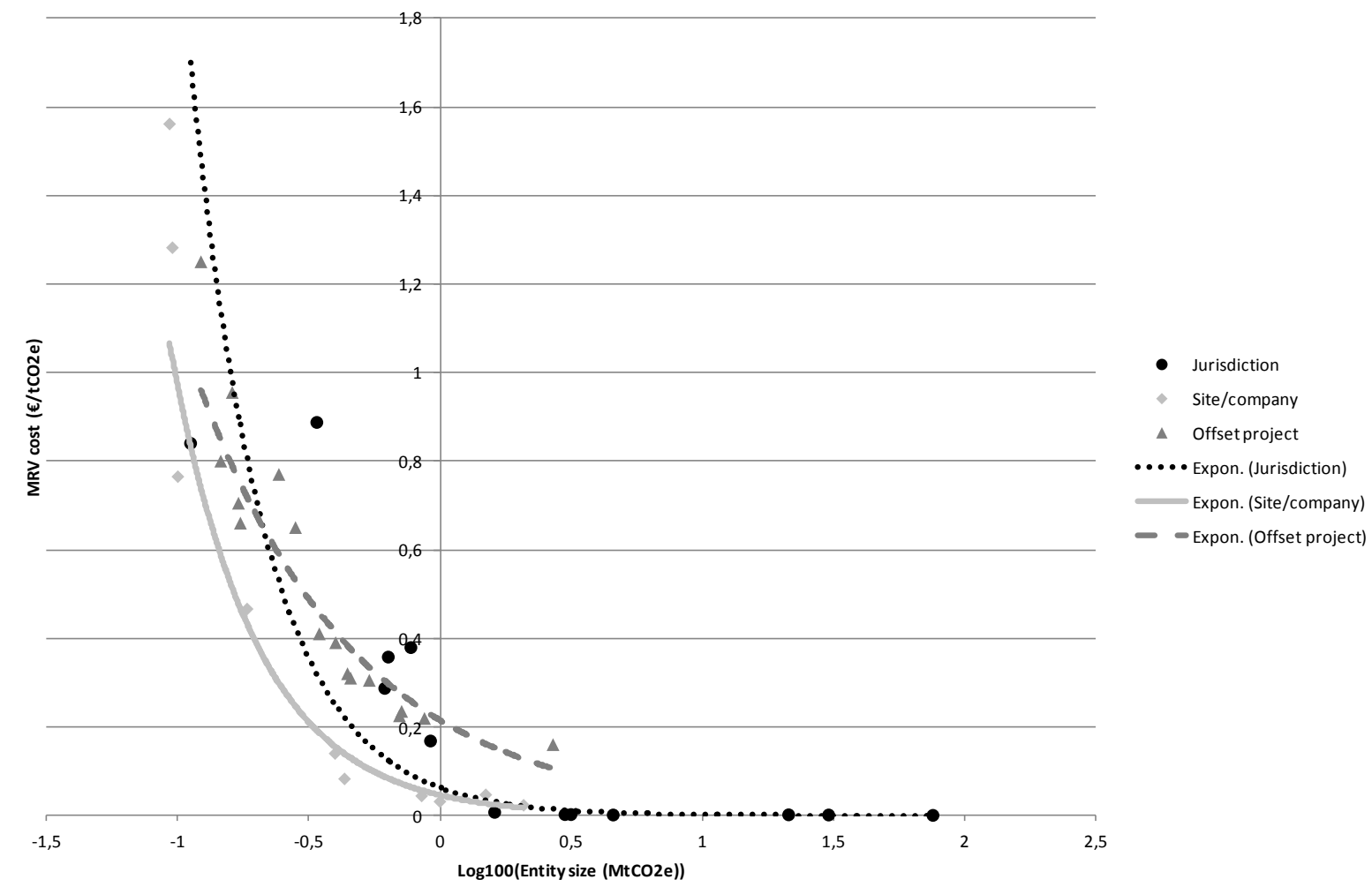

Note: Each point corresponds to one of the (cost, size) pairs retained in $\left(^{1}\right)$. It can be either an average for a give size range (e.g. EU ETS, CDM), or the estimated value for a specific entity (e.g. Germany's national GHG inventory, a specific jurisdictional REDD project, ...). As a result, all points do not have the same representativeness. The full list of pairs is provided in Table S5.

Sources: see Table 1 and $\left({ }^{1}\right)$.

Figure 5. Typology of materiality provisions across carbon pricing and management mechanisms (CPMs)

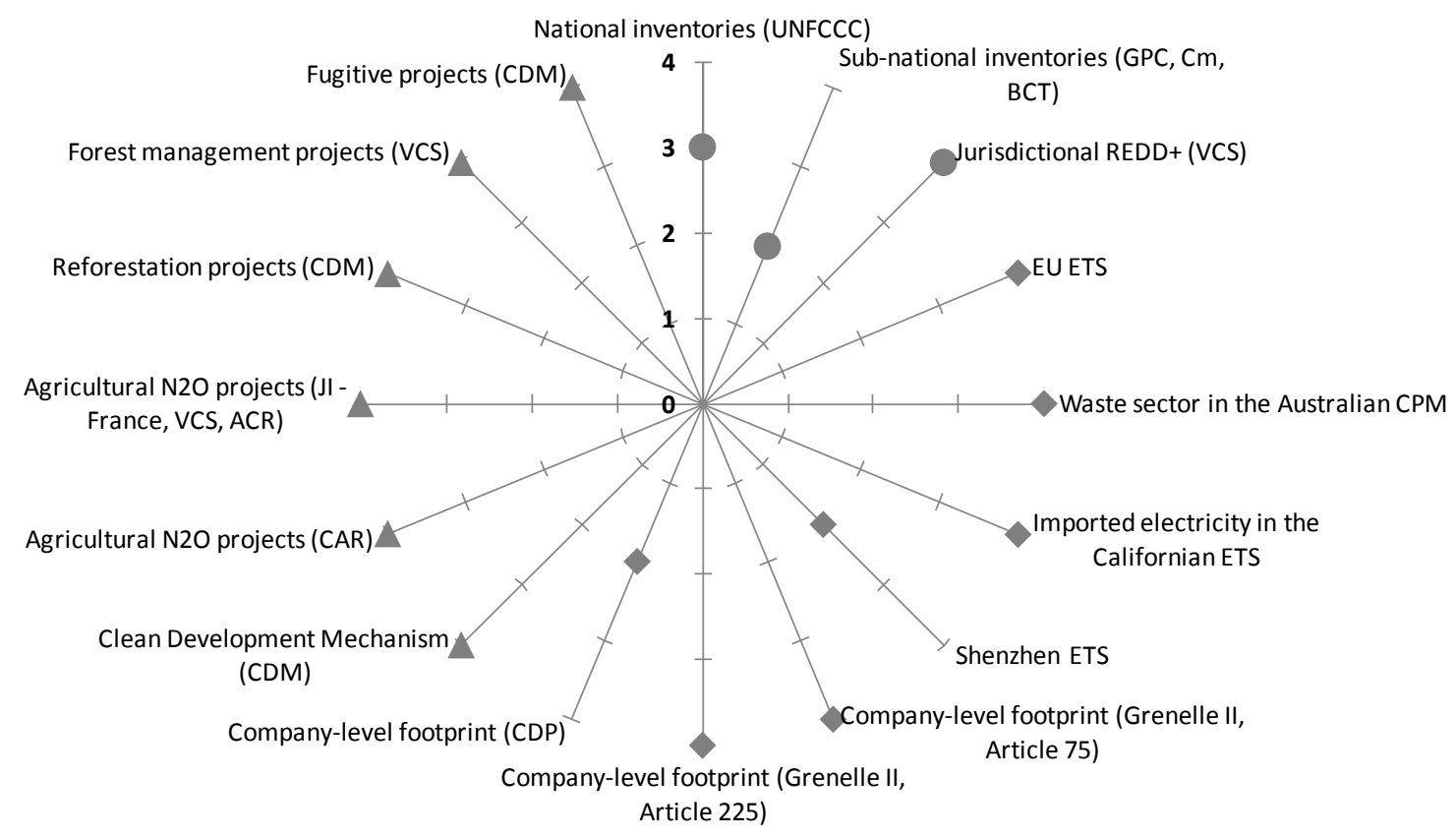




\section{Type of materiality provisions}

1 More stringent requirements for smaller sources

2 No rules to adapt requirements stringency

3 Qualitative rules

4 Quantitative thresholds reducing stringency for smaller sources

\section{Scale of the CPM}

Jurisdictional scale

Site/companyscale

$\triangle$ Offset project scale

For a detailed justification of the typology, see Table S4.

Sources: UNFCCC ${ }^{6}, \mathrm{GPC}^{64}, \mathrm{Cm}^{65}, \mathrm{BCT}^{66}, \mathrm{VCS}^{67,79}, \mathrm{MRR}^{10}, \mathrm{NGER}^{69}, \mathrm{MRR}^{15}, \mathrm{SZDB} / \mathrm{Z} \mathrm{69}^{70}$, Grenelle II Article $75^{71}$, Grenelle II - Article $225^{71}, \mathrm{CDP}^{73}, \mathrm{CDM}^{80}, \mathrm{CAR}^{81}, \mathrm{ACR}^{77}, \mathrm{VCS}^{76}, \mathrm{JI}^{78}, \mathrm{CDM}^{74,85,86}, \mathrm{VCS}^{18,76,87}, \mathrm{CDM}^{19}$. 


\section{Supplementary online materials}

\subsection{Forty one systematic questions asked for each of the scheme reviewed}

N.B.: The detailed answers to each of these questions for each of the schemes reviewed is available in $\left(^{1}\right)$.

\section{Context}

\begin{tabular}{|l|l|}
\hline Regulator & $\begin{array}{l}\text { The regulator is the entity which sets the MRV rules } \\
\text { and/or guidelines. In most cases, the entity also set } \\
\text { the rules of the system in general. There can b } \\
\text { several regulators for the same system (eg. UNFCCC } \\
\text { COP and IPCC for national greenhouse gas } \\
\text { inventories). }\end{array}$ \\
\hline Type and level of incentive to comply & $\begin{array}{l}\text { The type and severity of the punishments when non- } \\
\text { compliance is detected (eg. inability to use the Kyoto } \\
\text { flexibility mechanisms for national greenhouse } \\
\text { inventories). }\end{array}$
\end{tabular}

Entities concerned

Type of entity, number of entities, related market value

Sectors concerned

Gases concerned

Overall MRV costs

Monitoring

\begin{tabular}{|l|c|}
\hline Rules & $\begin{array}{c}\text { References of the official documents setting the } \\
\text { monitoring rules for the system. }\end{array}$
\end{tabular}

\begin{tabular}{|l|l|}
\hline Other reference documents & Document references (i.e. ISO, GHG protocol, etc?)
\end{tabular}

Uncertainty requirements

Precision of monitoring required under the system, if applicable, expressed in \% or tCO2e. In most cases, it will be a range of values varying with sectors, gases or categories.

Achieved uncertainty range

Precision of monitoring achieved under the system, if applicable, expressed in \% or tCO2e. In most cases, it will be a range of values varying with sectors, gases or categories.

Cost range

Estimate of current costs of monitoring, expressed in $€$ / country or site or company or project or tCO2e. The precise elements included in this cost estimate are provided on a case by case basis.

Scope

Scope of the emissions monitored. Three elements are specified:

A. Scope 1, 2 or 3 according to the definition of the GHG protocol $(1=$ direct emissions, $2=$ direct emissions and emissions related to 


\begin{tabular}{|c|c|}
\hline & $\begin{array}{l}\text { electricity consumption, } 3=\text { direct and } \\
\text { indirect emissions). } \\
\text { B. Territorial/jurisdictional vs } \\
\text { patrimonial/operational (territorial emissions } \\
\text { are the emissions occurring on the territory of } \\
\text { a given jurisdiction, no matter who is } \\
\text { responsible for these emissions (eg. } \\
\text { emissions of an administrative region), } \\
\text { whereas operational emissions corresponds to } \\
\text { the emissions of the entity itself (eg. } \\
\text { buildings, staff and activities of a regional } \\
\text { council). } \\
\text { C. Site vs entity: are the emissions from a type } \\
\text { of site monitored or rather emissions from a } \\
\text { type of entity? }\end{array}$ \\
\hline Frequency & Frequency of monitoring (daily, monthly, yearly, ...). \\
\hline Source for activity data & $\begin{array}{l}\text { What are the primary sources of information for } \\
\text { activity data? }\end{array}$ \\
\hline Uncertainty range for activity data & $\begin{array}{c}\text { Precision of monitoring required under the system, if } \\
\text { applicable, expressed in } \% \text { or tCO2e. In most cases, it } \\
\text { will be a range of values varying with sectors, gases or } \\
\text { categories. }\end{array}$ \\
\hline Source for emission factors & $\begin{array}{l}\text { What are the primary sources of information for } \\
\text { activity data? }\end{array}$ \\
\hline Uncertainty range for emission factors & $\begin{array}{c}\text { Precision of monitoring required under the system, if } \\
\text { applicable, expressed in } \% \text { or } \mathrm{tCO} 2 \mathrm{e} \text {. In most cases, it } \\
\text { will be a range of values varying with sectors, gases or } \\
\text { categories. }\end{array}$ \\
\hline Direct measurement & $\begin{array}{l}\text { Direct measurement is the measurement of the gas } \\
\text { itself with a sensor (often optical), possibly integrated } \\
\text { in an intelligent data assimilation system. Is direct } \\
\text { measurement allowed or mandatory in the system? } \\
\text { Under what conditions? Is it used or not used in } \\
\text { practice? }\end{array}$ \\
\hline Incentives to reduce uncertainty & $\begin{array}{c}\text { Is there an incentive to improve monitoring precision } \\
\text { built in the rules (eg. a conservativeness principle } \\
\text { increasing carbon debits in proportion to monitoring } \\
\text { uncertainty)? }\end{array}$ \\
\hline $\begin{array}{l}\text { Is requirements stringency adapted to the amount of } \\
\text { emissions at stake (materiality)? }\end{array}$ & $\begin{array}{l}\text { It makes good economic sense to be most stringent on } \\
\text { the largest and most concentrated sources of emissions } \\
\text { as the cost of monitoring tends to decrease with the } \\
\text { concentration of emissions (economies of scale). Is } \\
\text { this reflected in the rules/guidelines (eg. decreasing } \\
\text { precision demand with decreasing installation size)? }\end{array}$ \\
\hline \multicolumn{2}{|c|}{ Reporting } \\
\hline Rules & $\begin{array}{l}\text { References of the official documents setting the } \\
\text { reporting rules for the system. }\end{array}$ \\
\hline Other reference documents & Document references (i.e. ISO, GHG protocol, etc?) \\
\hline
\end{tabular}




\begin{tabular}{|c|c|}
\hline Format & $\begin{array}{c}\text { Description of the common reporting format if } \\
\text { relevant. }\end{array}$ \\
\hline Level of source disaggregation & $\begin{array}{l}\text { Quantitative explanation (number of sites, production } \\
\text { units, spatial resolution/aggregation, ...). There may } \\
\text { be a difference between the required reporting level of } \\
\text { disaggregation and the published level of aggregation. }\end{array}$ \\
\hline \multicolumn{2}{|l|}{ Frequency } \\
\hline Timeline & $\begin{array}{c}\text { Key dates with regards reporting (eg. reporting } \\
\text { deadline for year XX). }\end{array}$ \\
\hline Language & Possible languages for reporting. \\
\hline $\begin{array}{l}\text { Is requirements stringency adapted to the amount of } \\
\text { emissions at stake (materiality)? }\end{array}$ & $\begin{array}{l}\text { It may make good economic sense to be most } \\
\text { stringent on the largest and most concentrated sources } \\
\text { of emissions as the cost of reporting tends to decrease } \\
\text { with the concentration of emissions (economies of } \\
\text { scale). Is this reflected in the rules/guidelines (eg. } \\
\text { decreasing reporting frequency with decreasing } \\
\text { installation size)? }\end{array}$ \\
\hline Cost range & $\begin{array}{c}\text { Estimate of current costs of reporting, expressed in } € / \\
\text { country or site or company or project or tCO2e. The } \\
\text { precise elements included in this cost estimate are } \\
\text { provided on a case by case basis. }\end{array}$ \\
\hline \multicolumn{2}{|c|}{ Verification } \\
\hline Rules & $\begin{array}{l}\text { References of the official documents setting the } \\
\text { verification rules for the system. }\end{array}$ \\
\hline Other reference documents & Document references \\
\hline Format & $\begin{array}{l}\text { Description of the common verification format if } \\
\text { relevant. }\end{array}$ \\
\hline \multicolumn{2}{|l|}{ Frequency } \\
\hline Timeline & $\begin{array}{c}\text { Key dates with regards verification (eg. verification } \\
\text { deadline for year XX). }\end{array}$ \\
\hline Language & Possible languages for verification. \\
\hline Accredited entities for verification & $\begin{array}{c}\text { Description of the procedure and key criteria for } \\
\text { obtaining accreditation (if relevant). Examples of } \\
\text { accredited entities. }\end{array}$ \\
\hline Control of accredited entities & $\begin{array}{l}\text { Description of the procedure and key criteria for } \\
\text { maintaining accreditation (if relevant). Examples of } \\
\text { reason for suspension (if relevant). }\end{array}$ \\
\hline Cost of accreditation & $\begin{array}{c}\text { Cost estimates of obtaining and maintaining the } \\
\text { accreditation ( } € \text { per year). }\end{array}$ \\
\hline Support of accredited entities & $\begin{array}{l}\text { Description of the type of support that accredited } \\
\text { entities receive, and from whom they receive it (if }\end{array}$ \\
\hline
\end{tabular}




\begin{tabular}{|l|c|}
\hline $\begin{array}{l}\text { Is requirements stringency adapted to the amount of } \\
\text { emissions at stake (materiality)? }\end{array}$ & $\begin{array}{c}\text { relevant). } \\
\text { It may make good economic sense to be most } \\
\text { stringent on the largest and most concentrated sources } \\
\text { of emissions as the cost of verification tends to } \\
\text { decrease with the concentration of emissions } \\
\text { (economies of scale). Is this reflected in the } \\
\text { rules/guidelines (eg. materiality/de minimis rules)? }\end{array}$ \\
\hline Cost range & $\begin{array}{c}\text { Estimate of current costs of verification, expressed in } \\
€ / \text { country or site or company or project or tCO2e. } \\
\text { The precise elements included in this cost estimate are } \\
\text { provided on a case by case basis. }\end{array}$ \\
\hline
\end{tabular}




\subsection{Tables}

Table S 1. Verification requirements across carbon pricing mechanisms and management schemes

Legend for the column "type of verification requirements"

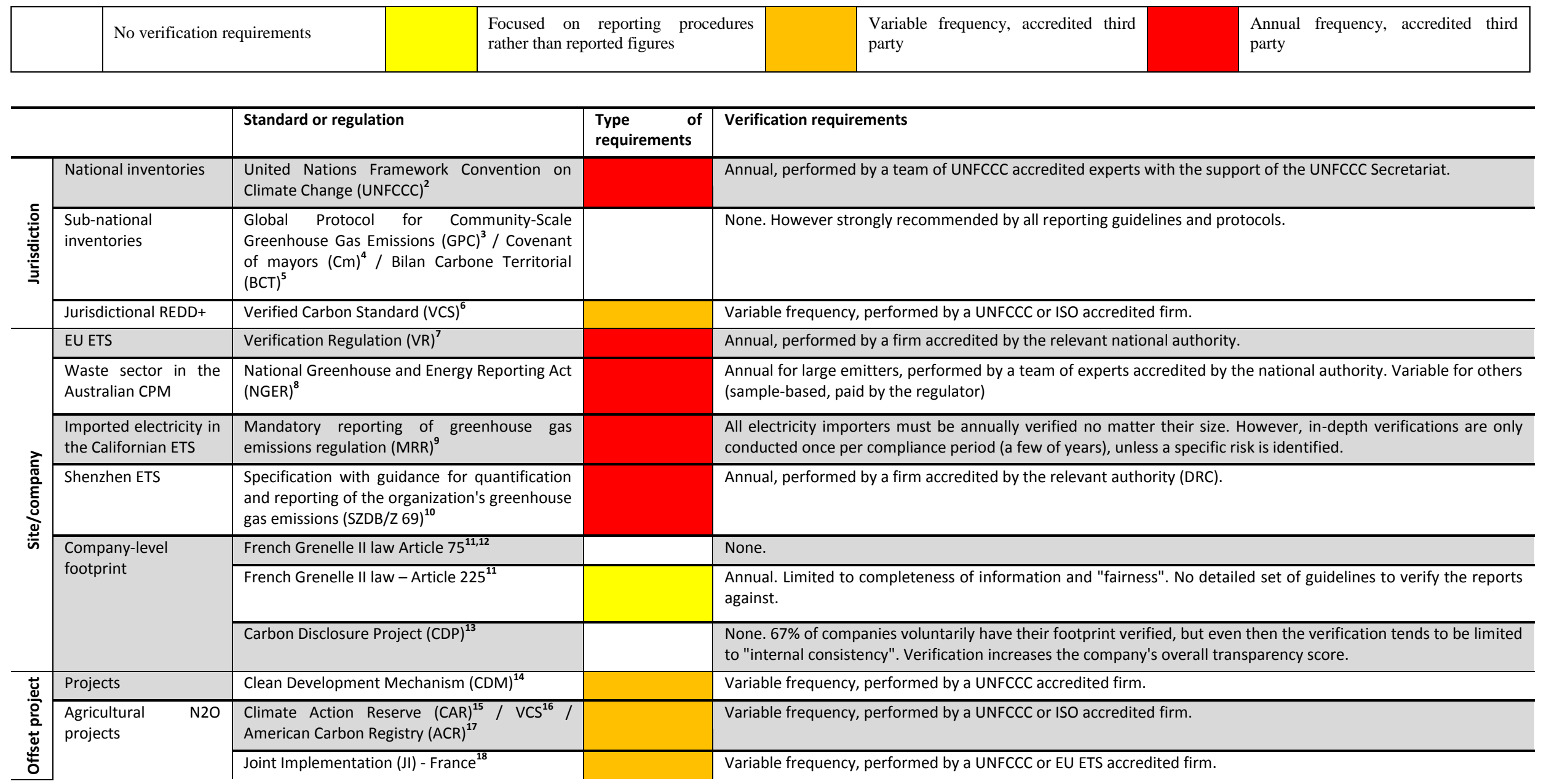




\begin{tabular}{|c|c|c|}
\hline Reforestation projects & $\mathrm{CDM}^{14}$ & Variable frequency, performed by a UNFCCC accredited firm. \\
\hline $\begin{array}{l}\text { Forest management } \\
\text { projects }\end{array}$ & $\mathrm{VCS}^{16}$ & Variable frequency, performed by a UNFCCC or ISO accredited firm. \\
\hline Fugitive projects & $\mathrm{CDM}^{14}$ & Variable frequency, performed by a UNFCCC accredited firm. \\
\hline
\end{tabular}


Table S 2. Type of uncertainty requirements across carbon pricing mechanisms and management schemes

Legend for the column "type of uncertainty requirements"

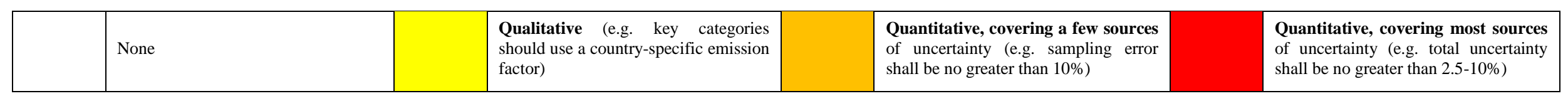

For details on acronyms, please refer to Table $\mathrm{S} 1$.

\begin{tabular}{|c|c|c|c|c|}
\hline & & $\begin{array}{l}\text { Standard } \\
\text { regulation }\end{array}$ & $\begin{array}{l}\text { Type of } \\
\text { requirements }\end{array}$ & Formal Requirements \\
\hline \multirow{3}{*}{ 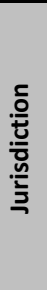 } & National inventories & UNFCCC $^{19}$ & & Key categories must use at least Tier 2. General objective to reduce uncertainty over the long run. \\
\hline & $\begin{array}{l}\text { Sub-national } \\
\text { inventories }\end{array}$ & $\begin{array}{l}\mathrm{GPC}^{3} / \mathrm{Cm}^{4} / \\
\mathrm{BCT}^{5}\end{array}$ & & None. \\
\hline & Jurisdictional REDD+ & $\operatorname{vcs}^{20}$ & & $\begin{array}{l}\text { Accuracy of land classification must be at least } 75 \% \text {. If activity-based accounting (only baseline is monitored at jurisdictional level), a } \\
\text { deduction is applied if the uncertainty of emissions factor exceeds } 30 \% \text {. If land-based accounting (full jurisdictional MRV), a deduction is } \\
\text { applied if the total uncertainty of baseline emissions exceeds } 50 \% \text {. IPCC default emission factors (Tier 1) can only be used for sources } \\
\text { representing less than } 15 \% \text { of total carbon stocks. }\end{array}$ \\
\hline \multirow{5}{*}{ 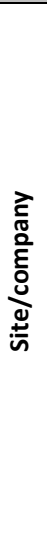 } & EU ETS & $\begin{array}{l}\text { Monitoring and } \\
\text { Reporting } \\
\text { Regulation } \\
(\text { MRR) }\end{array}$ & & $\begin{array}{l}\text { Uncertainty on activity data must be below } 1.5-15 \% \text {, depending on the size of the emission source. Uncertainty requirements on emission } \\
\text { factors may be qualitative (e.g. mandatory use of a given value) or quantitative (e.g. } 1 \% \text { for the carbon content of fuels, minimum } \\
\text { frequency for fuel sampling). Overall uncertainty must be below } 2.5-10 \% \text { if a direct measurement approach is used. }\end{array}$ \\
\hline & $\begin{array}{l}\text { Waste sector in the } \\
\text { Australian CPM }\end{array}$ & NGER $^{8}$ & & $\begin{array}{l}\text { No explicit requirements beyond a qualitative objective to minimize uncertainty. However, the relevant Australian or international } \\
\text { measurement standards must be applied when facility-specific emission factors are used. }\end{array}$ \\
\hline & $\begin{array}{l}\text { Imported electricity in } \\
\text { the Californian ETS }\end{array}$ & $\mathrm{MRR}^{9}$ & & $\begin{array}{l}\text { Overall uncertainty of electricity meters at facility level must be lower than } 5 \% \text {. Otherwise, no requirements on the source of emissions } \\
\text { itself beyond the proof of origin (NERC e-tag) and the requirements applied in the jurisdiction where electricity is produced (e.g. US EPA } \\
\text { GHG Reporting Rule). }\end{array}$ \\
\hline & Shenzhen ETS & $\mathrm{SZDB} / \mathrm{Z} 69^{10}$ & & $\begin{array}{l}\text { None yet specified. In addition, the use of default factors is always allowed, and therefore likely to be largely used since it is cheaper both } \\
\text { per se and because it fits well with the existing reporting on energy use. }\end{array}$ \\
\hline & $\begin{array}{l}\text { Company-level } \\
\text { footprint }\end{array}$ & $\begin{array}{l}\mathrm{CDP}^{13} / \text { Grenelle II } \\
\text { Article } 225 \quad \& \\
75^{11,12}\end{array}$ & & None. \\
\hline \multirow{3}{*}{ 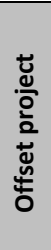 } & Projects & $\mathrm{CDM}^{22,23}$ & & $\begin{array}{l}\text { No explicit requirement in the overarching guidelines except for sampling and survey for which uncertainty must be below } 10 \% \text {. } \\
\text { Sub-sector specific calculation tools and methodologies may introduce either qualitative - through the mandatory use of a given method or } \\
\text { meter - or quantitative requirements but none is systematic. }\end{array}$ \\
\hline & Agricultural & $\begin{array}{l}\mathrm{CAR}^{24} / \mathrm{VCS}^{25} / \\
\mathrm{ACR}^{26}\end{array}$ & & $\begin{array}{l}\text { A deduction is applied if the uncertainty associated with the emission factor exceeds } 15 \% \text {. For activity data, projects rely on data reported } \\
\text { and verified under other existing regulations which set their own requirements (e.g. federal or state BMP programs). }\end{array}$ \\
\hline & & $\mathrm{Jl}-$ France $^{27}$ & & For activity data, projects rely on data reported and verified under the Common agricultural policy which sets its own requirements. \\
\hline
\end{tabular}




\begin{tabular}{|c|c|c|c|}
\hline & $\begin{array}{l}\text { Standard or } \\
\text { regulation }\end{array}$ & $\begin{array}{l}\text { Type of } \\
\text { requirements }\end{array}$ & Formal Requirements \\
\hline Reforestation projects & $\mathrm{CDM}^{28,29}$ & & Depends on methodologies: either a fixed $10 \%$ maximum or a deduction based on the sampling error on tree biomass. \\
\hline $\begin{array}{l}\text { Forest management } \\
\text { projects }\end{array}$ & $\operatorname{VCS} S^{30,31}$ & & $\begin{array}{l}\text { In some methodologies, the overall uncertainty - including model errors such as allometry - is considered in the deduction factor. In others, } \\
\text { the approach is similar to reforestation projects under the CDM and limited to sampling error. }\end{array}$ \\
\hline Fugitive projects & $\mathrm{CDM}^{32}$ & & If gas flow rate is measured (approach 2), a deduction is applied based on the uncertainty of gas flow rate measurement. \\
\hline
\end{tabular}

Table S 3. Incentives to reduce monitoring uncertainty across carbon pricing mechanisms and management schemes

Legend for the column "type of incentive to reduce uncertainty"

\begin{tabular}{|c|c|c|c|}
\hline None & $\begin{array}{l}\text { Qualitative (e.g. general principle of } \\
\text { "continuous improvement") }\end{array}$ & $\begin{array}{l}\text { Indirect (e.g. through a conservative } \\
\text { emission factor) and quantitative, } \\
\text { but covering only a few sources of } \\
\text { uncertainty. }\end{array}$ & $\begin{array}{l}\text { Direct (e.g. deduction factor) and } \\
\text { quantitative, covering most sources } \\
\text { of uncertainty. }\end{array}$ \\
\hline
\end{tabular}

For details on acronyms, please refer to Table $\mathrm{S} 1$.

\begin{tabular}{|c|c|c|c|c|}
\hline & & $\begin{array}{l}\text { Standard } \\
\text { regulation }\end{array}$ & $\begin{array}{l}\text { Type of } \\
\text { incentive }\end{array}$ & Requirements \\
\hline \multirow{3}{*}{ 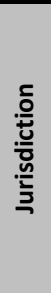 } & National inventories & UNFCCC $^{19}$ & & Key categories must use at least Tier 2 . General objective to reduce uncertainty over the long run. \\
\hline & $\begin{array}{l}\text { Sub-national } \\
\text { inventories }\end{array}$ & $\mathrm{GPC}^{3} / \mathrm{Cm}^{4} / \mathrm{BCT}^{5}$ & & None. \\
\hline & Jurisdictional REDD+ & $\mathrm{VCS}^{20}$ & & $\begin{array}{l}\text { "If activity-based accounting (only baseline is monitored at jurisdictional level), a deduction is applied if the uncertainty of emissions } \\
\text { factor exceeds } 30 \% \text {. } \\
\text { If land-based accounting (full jurisdictional MRV), a deduction is applied if the total uncertainty of baseline emissions exceeds } 50 \% \text {. } \\
\text { IPCC default emission factors (Tier 1) can only be used for sources representing less than } 15 \% \text { of total carbon stocks. }\end{array}$ \\
\hline \multirow{4}{*}{ 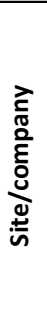 } & EU ETS & $\mathrm{MRR}^{21}$ & & None once the mandatory threshold is met. A principle of "continuous improvement" is nevertheless embedded in the MRR. \\
\hline & $\begin{array}{l}\text { Waste sector in the } \\
\text { Australian CPM }\end{array}$ & NGER ${ }^{8}$ & & Incentive to upgrade to method 2 when methane capture is higher than $75 \%$. \\
\hline & $\begin{array}{l}\text { Imported electricity in } \\
\text { the Californian ETS }\end{array}$ & $\mathrm{MRR}^{9}$ & & $\begin{array}{l}\text { None, unless the source is cleaner than the emission factor for unspecified sources, in which case there is an incentive to upgrade to } \\
\text { "specified source". Inversely, there is an incentive to maintain a high uncertainty "unspecified" status if the source is dirtier than the } \\
\text { default emission factor. }\end{array}$ \\
\hline & Shenzhen ETS & $\mathrm{SZDB} / \mathrm{Z} 69^{10}$ & & $\begin{array}{l}\text { None yet specified. To the contrary, the use of uncertain default factors is always allowed, and therefore likely to be largely used since } \\
\text { it is cheaper both per se and because it fits well with the existing reporting on energy use. }\end{array}$ \\
\hline
\end{tabular}




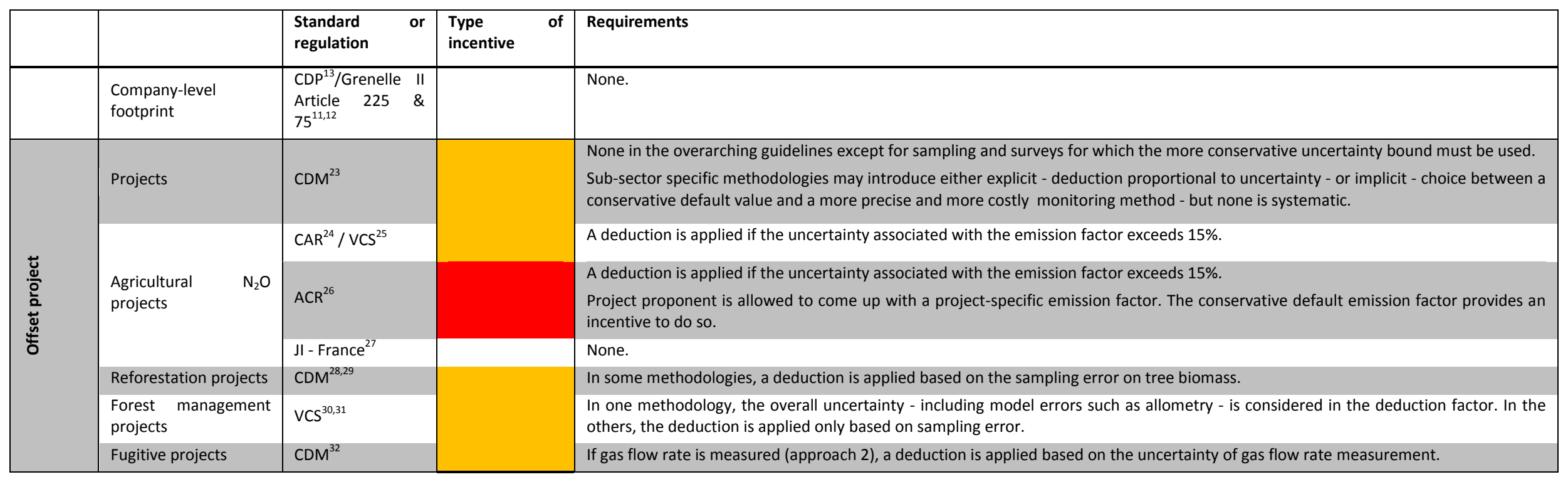


Table S 4. "Materiality" across carbon pricing mechanisms and management schemes

Legend for the column "type of materiality provisions"

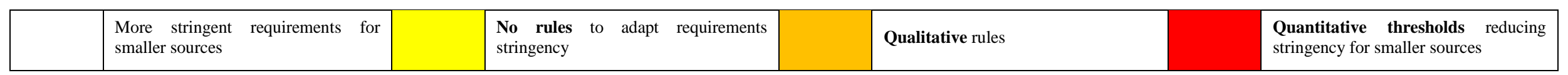

For details on acronyms, please refer to Table $\mathrm{S} 1$.

\begin{tabular}{|c|c|c|c|}
\hline & & Standard or regulation & Rules to adapt requirements stringency to the amount of emissions at stake \\
\hline \multirow{3}{*}{ 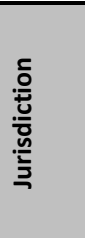 } & National inventories & UNFCCC $^{19}$ & None beyond the key category analysis ${ }^{7}$. \\
\hline & Sub-national inventories & $\mathrm{GPC}^{3} / \mathrm{Cm}^{4} / \mathrm{BCT}^{5}$ & None. \\
\hline & Jurisdictional REDD+ & $\mathrm{VCS}^{6,20}$ & $\begin{array}{l}\text { Pools which are not expected to become sources compared to the baseline need not be accounted. Small source can be } \\
\text { considered de minimis up to an overall } 10 \% \text { of emissions. Frequency of reporting and verification is flexible up to the } \\
\text { minimum five year return. Materiality between } 1 \% \text { (large projects) and } 5 \% \text { (small projects) during verification. }\end{array}$ \\
\hline \multirow{7}{*}{ 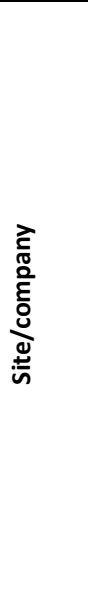 } & EU ETS & $\mathrm{MRR}^{21}$ & $\begin{array}{l}\text { Inclusion threshold based on various criteria (e.g. thermal input }>20 \mathrm{MW} \text { ) which can be quite low in terms of emissions } \\
\left(64 \% \text { of installations below } 25 \mathrm{ktCO}_{2} \mathrm{e} / \mathrm{yr} \text { and } 30 \% \text { below } 5 \mathrm{ktCO} \mathrm{CO}_{2} \mathrm{e} / \mathrm{yr}\right) \text {. Simplified requirements for installations below } 25 \\
\mathrm{ktCO} \mathrm{CO}_{2} \mathrm{e} / \mathrm{yr} \text {. Possibility to reduce stringency based on a cost/benefit analysis where benefit is a function of the amount of } \\
\text { emissions at stake. Materiality between } 2 \% \text { (large installations) and } 5 \% \text { (small installations) during verification. } \\
\text { Frequency of improvement report depends on installation size. }\end{array}$ \\
\hline & $\begin{array}{l}\text { Waste sector in the } \\
\text { Australian CPM }\end{array}$ & NGER $^{8}$ & $\begin{array}{l}\text { Inclusion threshold of } 25 \quad \mathrm{ktCO}_{2} \mathrm{e} / \mathrm{yr} \text { (or } 10 \quad \mathrm{ktCO}_{2} \mathrm{e} / \mathrm{yr} \text { in the vicinity of an already included landfill). } \\
\text { Verification is only systematic for facilities above } 125 \mathrm{ktCO}_{2} \mathrm{e} / \mathrm{yr} \text {. Smaller installations are verified on an arbitrary basis, to } \\
\text { the expense of the regulator. }\end{array}$ \\
\hline & $\begin{array}{l}\text { Imported electricity in } \\
\text { the Californian ETS }\end{array}$ & $M_{R R}{ }^{9}$ & $\begin{array}{l}\text { No inclusion threshold for electricity importers: all have to report and verify their emissions, no matter how small they are. } \\
\text { Materiality set at } 5 \% \text { of facility-level emissions during verification. }\end{array}$ \\
\hline & Shenzhen ETS & $\mathrm{SZDB} / \mathrm{Z} 69^{10}$ & None. \\
\hline & \multirow[t]{3}{*}{ Company-level footprint } & Grenelle II Article $75^{11}$ & Inclusion thresholds (e.g. private companies with more than 500 employees). \\
\hline & & Grenelle II - Article $225^{11}$ & $\begin{array}{l}\text { Inclusion thresholds (e.g. private companies with more than } 500 \text { employees and an annual income or assets worth more } \\
\text { than } € 100 \text { million). }\end{array}$ \\
\hline & & $\mathrm{CDP}^{13}$ & None. \\
\hline 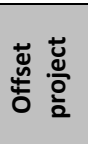 & Projects & $\mathrm{CDM}^{23}$ & $\begin{array}{l}\text { Reporting and verification frequency is up to the project developer. A minimal monitoring frequency is imposed based } \\
\text { reporting frequency. A higher monitoring frequency is therefore mandatory for larger projects which tend to opt for a high } \\
\text { reporting frequency. Simplified requirements for small-scale and micro-scale projects. Materiality threshold during } \\
\text { verification more gradual than EU ETS: from } 10 \%(<20 \mathrm{ktCO} 2 \mathrm{e} / \mathrm{yr}) \text { to } 0.5 \%\left(>500 \mathrm{ktCO}_{2} \mathrm{e} / \mathrm{yr}\right) \text {. }\end{array}$ \\
\hline
\end{tabular}

${ }^{7}$ A materiality provision has recently been inserted in the revised reporting guidelines which will be implemented in 2015 . Sources simultaneously below $0.05 \%$ of the national total and below $500 \mathrm{ktCO}_{2}$ e need not be estimated (decision 15/CP.17). Materiality is still absent from the verification of national GHG inventories. 


\begin{tabular}{|c|c|c|}
\hline & Standard or regulation & Rules to adapt requirements stringency to the amount of emissions at stake \\
\hline \multirow[t]{2}{*}{ Agricultural $\mathrm{N}_{2} \mathrm{O}$ projects } & $\mathrm{CAR}^{24}$ & $\begin{array}{l}\text { For monitoring, it is the contrary: an uncertainty adjustment factor makes requirements more stringent for projects with } \\
\text { fewer fields. Reporting must be done yearly or every two years for single-field projects. For site visit, it is the contrary: the } \\
\text { percentage of fields that must be visited by the auditor is inversely proportional to project size. Materiality threshold of } 5 \% \\
\text { during verification. }\end{array}$ \\
\hline & $\mathrm{ACR}^{17} / \mathrm{VCS}^{16} / \mathrm{Jl}^{18}$ & $\begin{array}{l}\text { Reporting and Verification frequency is up to the project developer. Materiality threshold between } 1 \% \text { and } 5 \% \text { for VCS } \\
\text { during verification. }\end{array}$ \\
\hline Reforestation projects & $\mathrm{CDM}^{14,28,29}$ & $\begin{array}{l}\text { Emissions from forestry operations are considered de minimis. Pools which are not a source need not be accounted (in } \\
\text { practice, only living biomass is accounted). MRV frequency is up to the project proponent. Materiality threshold between } \\
0.5 \% \text { and } 10 \% \text { during verification. }\end{array}$ \\
\hline $\begin{array}{l}\text { Forest management } \\
\text { projects }\end{array}$ & $\operatorname{VCS}^{16,30,31}$ & $\begin{array}{l}\text { Depending on the methodology, several sources may be considered de minimis (forestry operations, } \mathrm{CH}_{4} \text { and } \mathrm{N}_{2} \mathrm{O} \text { emissions } \\
\text { from biomass burning). Depending on the methodology, some pools need not be accounted. In any case, pools which are } \\
\text { not a source need not be accounted. MRV frequency is up to the project proponent. Materiality threshold between } 1 \% \text { and } \\
5 \% \text { during verification. }\end{array}$ \\
\hline Fugitive projects & $\mathrm{CDM}^{32}$ & No specific rules beyond what applies to all CDM projects (see above). \\
\hline
\end{tabular}


Table S 5. List of pairs for figure 5

\begin{tabular}{|c|c|c|c|c|c|}
\hline & & Standard or regulation & Case study / project type & $M R V \operatorname{cost}(€ / t \mathrm{CO} e)$ & Entity size (MtCO2e) \\
\hline \multirow{13}{*}{ 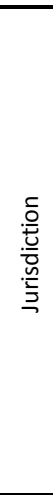 } & National inventories & UNFCCC & USA (Pacala et al., 2010, Bellassen and Stephan upcoming) & 0,000155513 & $\begin{array}{ll}5787,284 \\
\end{array}$ \\
\hline & National inventories & UNFCCC & Italy (Pacala et al., 2010, Bellassen and Stephan upcoming) & 0,001418588 & 458,202 \\
\hline & National inventories & UNFCCC & Germany (Pacala et al., 2010, Bellassen and Stephan upcoming) & 0,001026106 & 925,83 \\
\hline & Sub-national intentories & GHG Protocol / Covenant of mayors / Bilan Carbone Territorial & Dunkerque Grand Littoral (ABC 2013, Bellassen and Stephan upcoming) & 0,001 & 21 \\
\hline & Sub-national intentories & GHG Protocol / Covenant of mayors / Bilan Carbone Territorial & Lille Metropole (ABC 2013, Bellassen and Stephan upcoming) & 0,002 & 10 \\
\hline & Sub-national intentories & GHG Protocol / Covenant of mayors / Bilan Carbone Territorial & Marseille Provence Métropole (ABC 2013, Bellassen and Stephan upcoming) & 0,002 & 9 \\
\hline & Sub-national intentories & GHG Protocol / Covenant of mayors / Bilan Carbone Territorial & Grand Chalon (ABC 2013, Bellassen and Stephan upcoming) & 0,007 & 2,615 \\
\hline & Sub-national intentories & GHG Protocol / Covenant of mayors / Bilan Carbone Territorial & $\begin{array}{l}\text { Communauté de communes de la Vallée de Chamonix-Mont-Blanc (ABC 2013, } \\
\text { Bellassen and Stephan upcoming) }\end{array}$ & 0,84 & 0,0125 \\
\hline & Jurisdictional REDD+ & VCS & TBNP (Rendon et al. 2013, Bellassen and Stephan upcoming) & 0,36 & 0,40 \\
\hline & Jurisdictional REDD+ & VCS & SFM-MC (Rendon et al. 2013, Bellassen and Stephan upcoming) & 0,17 & 0,85 \\
\hline & Jurisdictional REDD+ & VCS & Noel Kempf (Rendon et al. 2013, Bellassen and Stephan upcoming) & 0,89 & 0,11 \\
\hline & Jurisdictional REDD+ & VCS & Juma (Rendon et al. 2013, Bellassen and Stephan upcoming) & 0,29 & 0,38 \\
\hline & Jurisdictional REDD+ & VCS & South East Asia, (Pearson et al. 2013, Bellassen and Stephan upcoming) & 0,38 & 0,60 \\
\hline \multirow{10}{*}{ 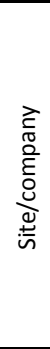 } & EUETS & MRR & Installations < 25 ktCO2e yr-1, Aether (2010) & 1,28 & 0,01 \\
\hline & EUETS & MRR & Installations between 25 and $50 \mathrm{ktCO}$ e yr-1, Aether (2010) & 0,47 & 0,03 \\
\hline & EUETS & MRR & Installations between 50 and $500 \mathrm{ktCO}$ e yr-1, Aether (2010) & 0,14 & 0,16 \\
\hline & EUETS & MRR & Installations > 500 ktCO2e yr-1, Aether (2010) & 0,05 & 2,24 \\
\hline & EUETS & MRR & Installations > 1,4 MtCO2e yr-1, Jaraite et al (2010) & 1,56 & 0,01 \\
\hline & EUETS & MRR & Installations between 0,067 and 1,4 MtCO2e yr-1, Jaraite et al (2010) & 0,04 & 0,73 \\
\hline & EUETS & MRR & Installations $<67 \mathrm{ktCO}$ e yr-1, Jaraite et al (2010) & 0,02 & 4,35 \\
\hline & EUETS & MRR & Installations emitting 10 ktCO2e yr-1, Heindl (2012) & 0,76 & 0,01 \\
\hline & EUETS & MRR & Installations emitting 187 ktCO2e yr-1, Heindl (2012) & 0,08 & 0,19 \\
\hline & EUETS & MRR & Installations emitting 1 MtCO2e yr-1, Heindl (2012) & 0,031258627 & 1 \\
\hline \multirow{16}{*}{ 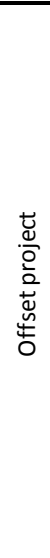 } & Projects & $\overline{C D M}$ & Biomass energy, Warnecke (2013) & 0,65 & 0,079 \\
\hline & Projects & $\mathrm{CDM}$ & Coal mine/bed methane, Warnecke (2013) & 0,235 & 0,51 \\
\hline & Projects & $\mathrm{CDM}$ & EE households, Warnecke (2013) & 0,955 & 0,026 \\
\hline & Projects & CDM & EE own generation, Warnecke (2013) & 0,32 & 0,197 \\
\hline & Projects & CDM & Fossil fuel switch, Warnecke (2013) & 0,225 & 0,491 \\
\hline & Projects & CDM & Hydro large-scale, Warnecke (2013) & 0,31 & 0,208 \\
\hline & Projects & $\mathrm{CDM}$ & Hydro small-scale, Warnecke (2013) & 0,705 & 0,029 \\
\hline & Projects & CDM & Landfill gas, Warnecke (2013) & 0,39 & 0,16 \\
\hline & Projects & CDM & Methane avoidance, Warnecke (2013) & 0,77 & 0,059 \\
\hline & Projects & CDM & N2O nitric acid, Warnecke (2013) & 0,305 & 0,289 \\
\hline & Projects & CDM & N2O adipic acid, Warnecke (2013) & 0,16 & 7,294 \\
\hline & Projects & CDM & Wind large-scale, Warnecke (2013) & 0,41 & 0,12 \\
\hline & Projects & CDM & Wind small-scale, Warnecke (2013) & 1,25 & 0,015 \\
\hline & Projects & CDM & Solar, Warnecke (2013) & 0,66 & 0,03 \\
\hline & Projects & CDM & Fugitives, Bellassen and Stepan (upcoming) & 0,219087126 & 0,762 \\
\hline & Projects & CDM & Reforestation, Bellassen and Stepan (upcoming) & 0,8 & 0,02125 \\
\hline
\end{tabular}




\subsection{References}

1. Accounting for Carbon: Monitoring, Reporting and Verifying Emissions in the Climate Economy. (Cambridge University Press, upcoming).

2. UNFCCC. Guidelines for the technical review of greenhouse gas inventories from parties included in annex I to the Convention. FCCC/CP/2002/8 (2002).

3. GHG Protocol. The Global Protocol for Community-Scale Greenhouse Gas Emissions - GPC Pilot Version 1.0.14 p (WRI/WBCSD, 2012).

4. Covenant of Mayors. How to Develop a Sustainable Energy Action Plan. 124 p (2010).

5. ADEME. Bilan Carbone ${ }^{\circledR}$ Entreprises - Collectivités -Territoires. Guide méthodologique version 6.1 - Objectifs et principes de comptabilisation. $116 \mathrm{p}$ (Agence de l'Environnement et de la Maîtrise de l'Energie, 2010).

6. VCS. JNR Validation and Verification Process, v3.0.14 p (Verified Carbon Standard, 2013).

7. European Commission. Commission Regulation 600/2012 on the verification of greenhouse gas emission reports and tonne-kilometre reports and the accreditation of verifiers pursuant to Directive 2003/87/EC of the European Parliament and of the Council. (2012).

8. Australian Government. National Greenhouse and Energy Reporting (Measurement), Amendment Determination 2013 (No. 1) - F2013L01191. (2013).

9. California Air Resource Board. ARB Mandatory Reporting Regulation. California Code of Regulations Title 17, CCR, sections 95100 - 95158, (2013).

10. Shenzhen People's Congress. Specification with guidance for quantification and reporting of the organization's greenhouse gas emissions. (2012).

11. Journal Officiel de la République Française. Loi $n^{\circ}$ 2010-788 du 12 juillet 2010 portant engagement national pour l'environnement. (2010).

12. MEDDE. Méthode pour la réalisation des bilans d'émissions de Gaz à effet de serre conformément à l'article 75 de la loi n²010-788 du 12 juillet 2010 portant engagement national pour l'environnement. $46 \mathrm{p}$ (Ministère de l'Ecologie, du Développement Durable et de l'Energie, 2012).

13. CDP. Guidance for companies reporting on climate change on behalf of investors \& supply chain members. 173 p (Carbon Disclosure Project, 2013).

14. UNFCCC. CDM Validation and Verification Standard - Version 03.0. 63 p (2012).

15. CAR. Program Manual. $42 \mathrm{p}$ (Climate Action Reserve, 2011).

16. VCS. VCS Standard. Version 3. $32 \mathrm{p}$ (Verified Carbon Standard, 2012).

17. ACR. The American Carbon Registry ${ }^{\circledR}$ Validation and Verification Guideline - Version 1.1. $64 \mathrm{p}$ (American Carbon Registry, 2012).

18. Journal Officiel de la République Française. Arrêté du 2 mars 2007 pris pour l'application des articles 3 à 5 du décret $n^{\circ}$ 2006-622 du 29 mai 2006 et relatif à l'agrément des activités de projet relevant des articles 6 et 12 du protocole de Kyoto - Version consolidée au 02 décembre 2012. (2012).

19. IPCC. 2006 IPCC guidelines for national greenhouse gas inventories. (IGES, 2006).

20. VCS. Jurisdictional and Nested REDD+ (JNR) Requirements - Version 3.1. $57 \mathrm{p}$ (Verified Carbon Standard, 2013). 
21. European Commission. Commission Regulation (EU) No 601/2012 of 21 June 2012 on the monitoring and reporting of greenhouse gas emissions pursuant to Directive 2003/87/EC of the European Parliament and of the Council. (2012).

22. UNFCCC. Standard for sampling and surveys for $c d m$ project activities - version 3.0. $8 \mathrm{p}$ (2011).

23. UNFCCC. CDM Project Standard for project design requirements including principles of monitoring - version 6.0. $61 \mathrm{p}$ (2014).

24. CAR. Nitrogen Management - Project Protocol, version 1.1. $138 \mathrm{p}$ (Climate Action Reserve, 2013).

25. VCS. Quantifying N2O Emissions Reductions in Agricultural Crops through Nitrogen Fertilizer Rate Reduction, v1.0. 56 p (Verified Carbon Standard, 2013).

26. ACR. Methodology for quantifying Nitous Oxide (N2O) emissions reductions from reduced use of nitrogen fertilizer on agricultural crops - Version 1. 45 p (American Carbon Registry, 2012).

27. In Vivo. Méthodologie spécifique aux projets de réduction des émissions de $\mathrm{N} 2 \mathrm{O}$ dues à la dénitrification des sols agricoles par insertion de légumineuses dans les rotations agricoles. $42 \mathrm{p}(2011)$.

28. UNFCCC. Afforestation and reforestation project activities implemented on lands other than wetlands - Version 03.0. $17 \mathrm{p}$ (2013).

29. UNFCCC. Afforestation and reforesta tion of lands except wetlands - Version 2.0. 15 p (2013).

30. VCS. VM0010 Methodology for Improved Forest Management: Conversion from Logged to Protected Forest - Version 1.2. 72 p (Verified Carbon Standard, 2013).

31. VCS. VM0012 Improved Forest Management in Temperate and Boreal Forests (LtPF) - Version 1.1. 83 p (Verified Carbon Standard, 2012).

32. UNFCCC. Approved baseline and monitoring methodology AM0023 - Leak detection and repair in gas production, pr ocessing, transmission, storage and distribution systems and in refinery facilities - Version 04.0.0. $21 \mathrm{p}$ (2011). 